\title{
Paternalist ve Dönüşümsel Liderlik Tarzlarının İşe Adanmışlık Üzerindeki Etkisinde, Sıkılık-Esneklik Değişkeninin Aracılık Rolü
}

DOI: $10.26466 /$ opus.597712

Kemal Can Kılıç* - Işıl Deniz Toker**- Duygu Karayel ${ }^{* * *}$-Tuğba Soyman**** Gözde Zengin*****

* Prof. Dr., Çukurova Üni. İ.I.B.F İşletme Böl. Yönetim Organizasyon A.B.D, Adana/ Türkiye

E-Posta: kcan@cukurova.edu.tr

ORCID: 0000-0003-1248-3321

** Y. L. Öğrencisi, Çukurova Üniversitesi Sosyal Bilimler Enstitüsü, Adana / Türkiye

E-Posta: isildeniztunc@gmail.com ORCID: 0000-0003-4165-2534

*** Y. L. Öğrencisi, Çukurova Üniversitesi Sosyal Bilimler Enstitüsü, Adana / Türkiye

E-Posta: duygukarayel06@gmail.com ORCID: 0000-0002-6506-4000

**** Y. L. Öğrencisi, Çukurova Üniversitesi Sosyal Bilimler Enstitüsü, Adana / Türkiye

E-Posta tugbasoyman@gmail.com ORCID: 0000-0002-7944-0986

***** Y. L. Öğrencisi, Çukurova Üniversitesi Sosyal Bilimler Enstitüsü, Adana / Türkiye

E-Posta gozdezengin@yahoo.com ORCID: $\quad$ 0000-0003-1699-9878

Öz

Bu çalı̧mada, gıda sektöründe faaliyet gösteren ve merkezde 150 çalışanı olan bir aile işletmesindeki paternalist ve dönüşümsel liderliğin, çalışanların işe adanmışlık tutumları üzerindeki etkisi ve sıkılık-esnekliğin bu etki üzerindeki aractlı rolü araştırılmıştır. 133 kişiden cevap alnan anket verisiyle yapılan analizler sonucunda; her iki liderlik tarzının da işe adanmışlığı pozitif ve anlamlı bir şekilde etkilediği, sıkılı-esneklik kültür boyutunun ise bu etkiye kısmi aracllk yaptı̆̆ belirlenmiştir.

Paternalist liderliğe kıyasla, dönüşümsel liderliğin işe adanmışlıktaki değişimi nispeten daha fazla açıklayabildiği, bu nedenle işe adanmışlı̆̆ın artırlması için paternalist liderliğin yanında dönüşümsel liderliğe eğilmenin iyi bir seçenek olabileceği görülmektedir. Dönüşümsel liderliğin alt boyutlarn ve işe adanmışlğ̆ın alt boyutları dikkate alındığında; entelektüel uyarım, ilham veren motivasyon ve bireysel ilginin işe adanmışlı̆̆ı alt boyutları (dinçlik, adanma, özümseme) üzerindeki etkisinde, sıkllk-esneklik kısmi aracllk rolüne sahiptir. İdeal etki alt boyutunun işe adanmışlı̆̆ı alt boyutları üzerindeki etkisinde ise sıkllk-esnekliğin bir aracllk rolü bulunmamaktadır. Paternalist liderliğin alt boyutları ve işe adanmışlı̆̆ın alt boyutları dikkate alındı̆̆ında aile ortamı yaratma, iş dışı konularda katılım, sadakat ve itaat boyutlarının işe adanmışlı̆̆ın üç alt boyutunun tümü üzerindeki etkisinde sıkllk-esneklik kısmi aracılık etkisine sahiptir. Otoriterlik alt boyutunun dinçlik ve adanmışlık alt boyutları üzerindeki etkisinde ise sıkllk-esneklik tam aracllk etkisine sahiptir.

Anahtar Kelimeler: Paternalist liderlik, Dönüşümsel liderlik, Sıkılık-esneklik, İşe adanmışlık 


\title{
Mediating Role of Tightness-Looseness on the Effect of Paternalistic and Transformational Leadership Style on Work Engagement
}

\begin{abstract}
In this study, effect of paternalistic leadership and transformational leadership on work engagement and mediating effect of tightness-looseness at a family owned company operating in food sector with 150 employees in the main facility is researched. According to results of analysis of the survey data collected from 133 respondents; both of the leadership styles has a positive and significant effect on work engagement and tightness-looseness culture has a partial mediating role on this effect.

Compared to paternalistic leadership, transformational leadership can explain change in work engagement better, so in order to increase work engagement, besides paternalistic leadership, focusing on transformational leadership seems a good alternative. Considering sub-dimensions of transformational leadership and work engagement; tightness-looseness has a partial mediating role on the effect of three subdimensions of transformational leadership (intellectual stimulation, inspirational motivation and individualized consideration) on sub-dimensions of work engagement (vigor, dedication, absorption). Tightness-looseness doesn't have a mediating effect on the effect of idealized influence sub-dimension of transformational leadership on sub-dimensions of work engagement. Considering sub-dimensions of paternalistic leadership and work engagement; tightness-looseness has a partial mediating role on the effect of three sub-dimensions of paternalistic leadership (family environment at workplace, involvement in non-work domain of employees' lives, expectation of loyalty and deference) on all three sub-dimensions of work engagement. Tightness-looseness have a full mediating effect on the effect of authoritarian leadership sub-dimension of paternalistic leadership on vigor and dedication sub-dimensions of work engagement.
\end{abstract}

Keywords: Paternalistic leadership, Transformational leadership, Tightness-looseness, Work engagement 


\section{Giriş}

Farklı kültürlerde, farklı liderlik tarzı beklentilerinin olduğunun anlaşılmasıyla birlikte, farklı değer ve kültürlere sahip toplumlardaki çalışanların hangi liderlik tarzlarını istedikleriyle ilgili araştırmalar yapılmaya başlanmıştır. Bu çalışmalar sonucunda, Batı'da daha nadir görülen paternalist liderlik tarzının, Asya ve Ortadoğu'da daha yaygın olduğu ortaya çıarılmıştır (Cerit, 2012). Bu çalışmada incelenecek olan araştırma değişkenlerinden ilki paternalist liderliktir. İkinci liderlik tarzı ise, yüksek değerlere yönlendirerek çalışanları motive eden, yüksek standartlar koyan ve vizyonu işaret ederek çalışanları beklentilerin ötesinde performans göstermeye yönlendiren dönüşümsel liderliktir (Sarros ve Santora, 2001). Sarros ve Santora, 2001 yılındaki çalışmalarında; başarılı sonuçlar için önemli olanın duruma göre liderlik tarzları arasında geçiş yapabilmek olduğunu belirtmiştir.

Bu çalışmada aracı değişken olarak değerlendirilecek olan sıkılık-esneklik, literatürde örgüt kültürünün alt boyutu olarak kabul görmüş (Gelfand, Nishii ve Raver, 2006; Aktaş, Gelfand ve Hanges, 2011) bununla birlikte dünyada ve Türkiye'de yapılan araştırmalarda da kullanılmakta olduğu tespit edilmiştir (Wasti ve Fiş, 2010). Örgüt kültürü kavramı, örgütlerin stratejik ve hayati faaliyetleri üzerinde önemli bir etkiye sahiptir (Üstün ve Kılıç, 2017).

Araştırmanın diğer temel değişkeni ise işe adanmışlıktır. İşe adanmışlık kavramı, literatürde ilk kez, tükenmişlik (burnout) kavramının zıttı bir kavram olarak ortaya atılmıştır (Gündüz, Çapri ve Gökçakan, 2013). Schaufeli, Martinez, Marques Pinto, Salanova ve Bakker (2002), yaptıkları çalışmada, pozitif psikolojideki gelişme sayesinde insanların güçlü yönlerini dikkate alan yaklaşımın, işe adanmışlık kavramını ortaya çıkardığını savunmaktadır. Bu çalışmada, paternalist ve dönüşümsel liderliğin işe adanmışlık üzerindeki etkisinde sıkılık-esneklik kültür boyutunun aracilık etkisi araştırılmaktadır.

Araştırma yapılan gıda sektörü firması, aile üyelerinin ortaklığından oluşan bir anonim şirkettir. Şirketin temel faaliyetlerinde etkin olan ve tüm çal1şanlar üzerinde de baskın bir etkisi görülen, aynı zamanda paternalist liderlik özellikleri ile şirkete yön verdiği gözlemlenen kişi şirketin sahibi ve yönetim kurulu başkanıdır ve ikinci kuşak yönetici olarak şirketin bütün faaliyetleri üzerinde güçlü bir etkiye sahiptir. Şirketin üçüncü kuşak yöneticisi olarak şirket yönetiminde aktif bir şekilde yer alan yönetim kurulu başkanının oğlu şirketin genel müdürü konumundadır. Genel müdür olarak aile şirketinin 
karşılaştı̆̆ problemlerin farkında olup, bilinçli ve önleyici çözümler üretmektedir. Yönetim kurulu başkanının kardeşi aynı zamanda şirketin de ortağıdır ve daha çok şirketin pazarlama ve tanıtım kısmından sorumlu olarak çalışmaktadır. Yönetimi aile üyelerinden oluşan şirkette aile şirketi olmanın farkındalığ 1 ile kurumun devamlılığ 1 için bir aile anayasası oluşturmaya çalışlmaktadır.

Çalışma kapsamında şirkette yapılan gözlemler ile yönetim kurulu başkanı ve çalışanlarla yapılan görüşmeler, şirket faaliyetlerinde paternalist liderlik tarzının baskın olduğu fikrini vermektedir. Araştırmacılar, yönetim kurulu başkanının; kontrolü seven, şirket içerisinde çok aktif olarak yer alan, üretimin her alanında olan, samimi, içten ve düşüncelerini doğrudan söyleyen bir lider olduğunu gözlemlemişlerdir. Şirket içerisinde kurallar konulduğu ancak sabit kurallar yerine, durumlara göre güncellenen kurallar olduğu ve yapılan görüşmelerde çalışanların bu kurallara uymakta zorlandığı belirlenmiştir. Formal yapının yanında informal yapı da aktiftir. Bu çerçevede her kademeden bütün çalışanlar yönetim kurulu başkanına doğrudan ulaşabilmektedirler. Şirket her ne kadar formal yapıyı güçlendirmeyi amaçlasa da şirket içerisinde daha çok esnek bir yapının oluştuğu gözlemlenmiştir. Şirket, faaliyetlerini mevcut pazara odaklanma ve derinleştirme üzerine sürdürmektedir. Bunun yanında ürün inovasyonunda da gelişim hedeflenmektedir.

\section{Literatür Taraması}

Gelfand (2007), paternalist liderliği, liderin hem bireysel hem profesyonel konularda rehberlik edip karşılığında bağlılık beklediği bir liderlik tarzı olarak tanımlamıştır. Farh ve Cheng (2000) ise, paternalist liderliği babacan yardımseverlik, disiplin ve otoritenin bir arada olduğu bir liderlik tarzı olarak tanımlamıştır. Pellegrini ve Scandura (2008), bu liderlik tarzında lider tarafından sergilenen yardımseverliğe, ilgiye ve korumaya karşılık astlardan bağlılık beklendiğini belirtmişlerdir (Cerit, 2012). Hindistan, Çin, Türkiye ve Pakistan'da yapılan çalışmaların sonucuna göre, paternalist liderlik otoriterlik anlamına gelmemekte, astların, liderin ilgi ve korumasına karşılık olarak uyum göstermelerini ifade etmektedir (Pellegrini ve Scandura, 2008).

Türkiye'de paternalist liderlikle ilgili yapılmış çeşitli çalışmalar (Aycan ve Paşa, 2003; Erben ve Ötken, 2014; Öner, 2009; Öge, Çetin ve Top, 2018) bulunmaktadır. Bunlardan Aycan ve Paşa (2003), 1200 civarında işletme öğrencisi 
ile yaptıkları çalışma sonucunda bu öğrenciler tarafından en çok tercih edilen liderlik tarzının sırasıyla karizmatik liderlik, katılımc liderlik, paternalist liderlik ve bürokratik liderlik olduğunu ortaya çıkarmışlardır. Öner (2009) ise yaptığı çalışmada hizmetkâr liderlik ve paternalist liderlik tarzları arasındaki ilişkiyi araştırmış, 300'ün üzerinde beyaz yaka orta düzey yönetici üzerinde yaptıkları bu çalışma sonucunda; hizmetkâr liderlik ve paternalist liderlik arasında pozitif korelasyon tespit etmiştir. Erben ve Ötken (2014), paternalist liderlik tarzı ile işe ilişkin iyilik arasındaki ilişkiyi ve bu ilişkide iş-yaşam dengesinin rolünü araştırmış ve bu ilişkide iş-yaşam dengesinin aracı rolü olmadığını bulmuşlardır. Öge vd. (2018) ise, yaptıkları çalışmada, paternalist liderlik ve iş yerinde yalnızlık (workplace loneliness) ile iş aile çatışması (work family conflict) arasındaki ilişkide, işe adanmışlığın aracı rolünü incelemişler ve işe adanmışlığın tam aracı etkisi olduğunu ortaya çıkarmışlardır.

Paternalist liderlik davranışın, farklı alt boyutlarda ve farklı ölçeklerle ölçen çalışmalar bulunmaktadır (Aycan, 2006; Aycan, vd., 2000; Aycan, Schyns, Sun, Felfe, Saher, 2013; Cheng, Chou, Wu, Huang ve Farh, 2004; Mathur, Aycan ve Kanungo, 1996; Pellegrini ve Scandura, 2006; Pellegrini ve Scandura, 2008). Bu çalışmada, Aycan, vd. (2013) tarafından geliştirilen 3 boyut altında 10 sorudan oluşan ölçeğin kısa versiyonuna ek olarak, Cheng, Chou, Wu, Huang ve Farh tarafından 2004 yılında geliştirilen ölçeğin otoriterlik alt boyutu kullanılmıştır. Değişkenin otoriterlik alt boyutu soruları Erben ve Ötken (2014)'in çalışmasından alınmıştır. Araştırma toplamda 17 soru ve dört alt boyuttan (iş yerinde aile ortamı yaratma -4 soru, iş dışı konularda katılım - 3 soru, sadakat ve itaat -3 soru, otoriterlik -7 soru) oluşmaktadır.

Araştırmamızın ikinci bağımsız değişkeni dönüşümsel liderliktir. Dönüşümsel liderlik kavramı, ilk kez 1973 yılında Dawnton'un İsyan Liderliği (Rebel Leadership) çalışmasında kullanılmıştır. Daha sonra bu kavram 1978 yılında Burns tarafından sistematize edilmiştir. Burns'e göre lider; ekip üyelerinde yüksek düzeyde moral, motivasyon ve performans sağlamaktadır, değişimin ustasıdır, vizyon sahibidir, öngörülüdür, vizyonunu ekibe benimseterek ekipte istek uyandırır. Burns lider odaklı yaklaşımdan uzaklaşılması gerektiğini, toplu bir amaca hizmet etmeyen liderliğin önemsiz olduğunu belirtmiştir (Eraslan, 2004). Dönüşümsel liderler, takipçilerinin amaç, beklenti ve isteklerine ulaşmalarını sağlayarak üstün performans göstermelerini sağlamaktadırlar. Amaç ve misyona bağlılık oluşturmada, ekip üyelerini etkilemede, tutum ve algıları değiştirmede, dönüşümsel liderlik etkili olmaktadır. 
Dönüşümsel liderlikte, sosyal değişim sayesinde her birey için sağlanacak faydanın da ötesinde, bireylerin motivasyonlarını, davranışlarını ve etik ihtiyaçlarını artıran bir tutum ve ortak amaç için hep birlikte dönüşüm söz konusudur. Dönüşümsel liderliğin 4 temel aşaması; değişim ihtiyacının tespiti, geçişin yönetilmesi, yeni bir vizyonun oluşturulması ve değişimin kurumsallaştırılması olarak belirtilmiştir (Gül ve Şahin, 2011). Dönüşümsel liderler, yalnızca performansa ve yeniliklere odaklanmazlar, aynı zamanda takipçilerinin güvenini ve mutluluğunu da artırmaya odaklanırlar. Dönüşümcü liderler, korku, baskı, kıskançlık gibi duygular yerine, barış, insancl yaklaşım ve eşitlik gibi yüksek değerler vasıtasıyla takipçilerini yönlendirirler (Kırel, 2001). Yüksek yenilikçiliğin olduğu ve tatmin edici örgütsel kültürlerde; insanlar güvenilirdir ve bir amaçları vardır, herkesin özgün bir katkısı vardır, karmaşık problemler mümkün olan en düşük seviyede çözülür varsayımlarına sahip dönüşümsel liderler görmek mümkündür. Dönüşümsel liderliğin 4 alt boyutu bulunmaktadır: ideal etki, ilham veren motivasyon, entelektüel uyarım ve bireysel ilgi (Bass ve Avolio, 1993). Dönüşümsel liderliğin gelişiminde, Bass (1985) tarafindan ortaya konan daha sonra Avolio (1999) ile birlikte güncelleme yaptıkları çok faktörlü liderlik ölçeği etkili olmuştur (Arslantaş ve Pekdemir, 2007). Bu çalışmada kullanılan ölçeğin soruları; çok faktörlü liderlik ölçeği (MLQ) temel alınarak oluşturulan ve çeşitli çalışmalarda kullanılmış olan ölçeklerden derlenmiştir (Baloğlu, Karadağ ve Gavuz, 2009; Gündüz, 2015; Yolaç, 2011). İdeal etki boyutunda 8 soru, ilham veren motivasyon, entelektüel uyarım ve bireysel ilgi boyutlarında 4 'er soru olmak üzere toplam 20 soru bulunmaktadır.

Gelfand vd. (2006), sıkılık-esneklik kavramını belirli bir topluluk içinde sosyal normların ve yaptırımların kapsam, önem ve etki gücü olarak tanımlamışlardır. Buna göre sıkılık ve esneklik kavramı birey davranışlarının sosyal norm ve yaptırımlardan ne derece etkilendiğini araştırmaktadır. Bu kavramı ilk defa kuramsallaştıran kişinin Pelto olduğu söylenebilir (Wasti ve Fiş, 2010). 1968 yılında konu üzerine araştırmalarını bilimsel bir makale haline çeviren Pelto'nun çalışmasına göre, sıkı toplumlarda normlar kesin bir şekilde belirlidir ve bu normlardan sapmaya tolerans gösterilmemektedir. Esnek toplumlarda ise normlar daha az sayıdadır ve normlardan sapmaya daha fazla tolerans gösterilmektedir (Üstün ve Kılıç, 2017). Pelto, toplumların sık1lık-esneklik skalasında farklı yerlere düştüklerini belirtmekte ve bir toplumun bu skaladaki yerini belirleyebilmek için çeşitli ölçütler önermektedir. Bu 
ölçümle birlikte, toplumlardaki sıkılık-esnekliğin farklı toplumsal boyutlarla (kişilik yapısı, olağan dışı davranışlar, vb.) ilişkisinin araştırılabileceğini belirtmektedir (Pelto, 1968). Khandwalla (1976) tarafından örgüt yapısında organikliği (esnekliği) ölçümlemek için geliştirilen ölçek, sıkılık-esnekliğin ölçümlenmesinde de kullanılabilecek bir araç olarak literatürde kabul görmüştür. Orijinalinde 7'li likert kullanılarak hazırlanan ölçekte iki uçlu 5 madde bulunmaktadır. Bu ölçekte yüksek olan değerler örgüt kültürünün daha esnek olduğu anlamına gelmektedir. İlk olarak Khandwalla (1976) tarafindan geliştirilen ölçek Wasti ve Fiş (2010) tarafından Türkçe'ye uyarlamıştır (Sakal ve Macit, 2018). Toplumsal normların çalışanlar üzerindeki etkisi henüz ölçümlenememektedir. Bununla beraber yukarıda literatürdeki yeri açıklanan sıkılık-esneklik yapısının bilinmesi çalışanların takdir edilme, toplumsal beğeni ve çevrenin olumlu tepkilerine verecekleri tepkilerin anlamlandırılmasında önemli bir kavram olarak karşımıza çıkmaktadır (Üstün ve Kılıç, 2017).

Gelfand vd. (2011) yaptıkları araştırmada Türkiye'nin kültürünü ortalamaya göre daha sıkı olarak belirlemişlerdir. Özeren, Özmen ve Appolloni (2013) de yaptıkları çalışmada, Türkiye'de mermer sektöründe örgüt kültürünün ortalamaya göre daha sıkı olduğunu belirlemişlerdir. Aycan ve Kanungo (2000), paternalist kültürlerde, astların görevinin koşulsuz şartsız liderin kurallarına uymak olduğunu belirtmişlerdir. Buradan hareketle, paternalist eğilimler gösteren toplumlarda, kural ve normlara uyumun önemli olduğunu ya da paternalist kültürlerde örgüt kültürünün daha sıkı olduğunu söylemek mümkündür (Özeren vd., 2013). Uz (2015) yaptığı çalışmada, 68 ülkenin sıkılık esneklik değerlerini karşılaştırmıştır. Sonucu raporlanan 65 ülke içerisinde, Türkiye en sıkı kültüre sahip 6. ülke olmuştur. Uluslararası literatürde olduğu gibi, Türkiye'de de liderlik tarzı ve örgüt kültürü arasındaki ilişkiyi araştıran çeşitli çalışmalar bulunmaktadır. Bu çalışmalarda, liderlik tarzlarının örgüt kültürü üzerinde anlamlı bir etkisinin olduğu bulunmuştur (Acar, 2013; Bakan, 2008; Barut ve Onay, 2018; Erdem ve Dikici, 2009). Schein (1992), örgüt liderlerinin örgüt kültürünü etkileyen en önemli faktör olduğunu ileri sürmüştür (Korkmaz, 2007). Acar (2013) ise çalışmasında, klan ve hiyerarşi kültürlerinin dönüşümcü liderlikten etkilendiğini bulmuştur. Aktaş, Gelfand ve Hanges (2016), sıkılık-esneklik ile katılımcı liderlik, otonom liderlik, karizmatik liderlik ve kendini koruyan liderlik arasındaki ilişkiyi araştırmıştır. Mittal (2015) yaptığı çalışmada, karizmatik liderlik ve dönü- 
şümsel liderlik ile, bireysellik-kollektivizm ve sıkılık-esneklik arasındaki ilişkiyi tartışmaktadır. Çalışmada, bireysel ve esnek kültürlerde, karizmatik liderliğin daha fazla geçerli olduğu, kollektivist ve sıkı kültürlerde ise dönüşümsel liderliğin daha fazla geçerli olduğu önermeleri ortaya atılmıştır.

Çalışmamızın bağımlı değişkeni literatürde "work engagement" olarak geçmektedir. Bu kavram Türkçe'ye, işe adanmışlık, işe angaje olma, işe tutkunluk, işe cezbolma, işe gönülden adanma gibi farklı şekillerde çevirilmiştir (Özkalp ve Meydan, 2015). Bu çalışmada ise "işe adanmışlık" ifadesi kullanılmaktadır. İşe adanmışlık; dinçlik (vigor), adanma (dedication) ve özümseme (absorption) alt boyutlarını içeren, işle ilgili pozitif bir zihin durumudur. Bununla birlikte işe adanma, anlık veya özel bir durum olmaktan çok, belirli bir nesneye, olaya, kişiye ve davranışa bağlı olmayan, sürekli bir duygusal-bilişsel durum olarak da tarif edilmektedir (Schaufeli, vd., 2002). İşe adanmış olan çalışanlar, işteki aktivitelerle enerjik ve etkili bir bağlantıları olduğunu hissederler ve işin gereklerini iyi bir şekilde karşılayabileceklerini düşünürler (Schaufeli ve Bakker, 2004). İşe adanmışlı̆̆ın alt boyutlarından ilki olan dinçlik; çalışırken sergilenen yüksek enerji seviyesi ve zihinsel dayanıklılığı ifade eder. Kişinin kendi isteğiyle çabasını işe yönlendirmesidir. İkinci boyut olan adanma; dikkate değer olma, şevk, ilham, gurur ve meydan okuma ile ilgilidir. Üçüncü ve son boyut olan özümseme ise; tüm dikkat ve ilgisini işe verme, odaklanma, zamanın hızlı akması ve kişinin işin kendisini alıp götürdügünü hissetmesi ile ilgilidir (Schaufeli, vd., 2002).

Bu çalışmada kullanılan işe adanmışlık ölçeği, Schaufeli vd. tarafından 2002'de, Maslach Tükenmişlik Ölçeği (Burnout Inventory) temel alınarak oluşturulmuştur (Çapri, Gündüz ve Akbay, 2014). Üç alt boyut ile oluşturulan ölçekte, dinçlik alt boyutunda 6 soru, adanma alt boyutunda 5 soru ve özümseme alt boyutunda 6 soru olmak üzere toplamda 17 soru bulunmaktadır (Schaufeli ve Bakker, 2004). Bu ölçeğin Türkçeye uyarlanması konusunda farklı çalışmalar bulunmaktadır (Bal, 2008; Erim, 2009; Güneșer, 2007; Oner, 2008; Turgut, 2011; Gündüz, Çapri ve Gökçakan, 2013). Bu çalışmada, Özkalp ve Meydan (2015) tarafından Schaufeli (2003)'nin yayınlamış olduğu İngilizce ölçeğin kısa versiyonunun Türkçe'ye tercüme edilmesiyle hazırlanan ölçek kullanılmıştır. Bu ölçek, tek boyut veya üç boyut olarak yüksek bir iç tutarlılık sergilemektedir ve yapı geçerliliğine sahiptir. Ölçeğin kısa versiyonunda, her boyut altında 3'er adet soru bulunmaktadır. (Özkalp ve Meydan, 2015). 
Literatürde, işe adanmışlık ve liderlik tarzları arasında ilişkiyi araştıran çeşitli çalışmalar bulunmaktadır (Babcock-Roberson ve Strickland, 2010; Cenkçi ve Özçelik, 2015; Enwereuzor, Ugwu ve Eze, 2018; Ghadi, Fernando ve Caputi; 2011; Korkmaz, Gökdeniz ve Zorlu, 2018; Salanova, Lorente, Chambel ve Martinez, 2011; Shu, 2015; Zhu, Avolio ve Walumba; 2009). Korkmaz, vd. (2018) yaptıkları çalışmada, paternalist liderliğin alt boyutları ile örgütsel özdeşleşme düzeyleri ve işe adanmışlığın aracı etkisini araştırmışlardır. Araştırma sonuçlarına göre, otoriter liderlik alt boyutu ve özdeşleşme arasında anlamlı bir ilişki bulunamamıştır. Yardımsever liderlik alt boyutu ile özdeşleşme arasında anlamlı bir ilişki bulunmuş ve işe adanmışlığın tam aracı rolü sergilediği ölçülmüştür. Son olarak ahlaki liderlik alt boyutu ile özdeşleşme arasında anlamlı ve pozitif bir ilişki bulunmuş ve işe adanmışlığın kısmi aracı etkisi olduğu ölçülmüştür. Cenkçi ve Özçelik (2015) yaptıkları çalışmada, paternalist liderliğin alt boyutları olan yardımsever liderlik ve otoriter liderliğin, işe adanmışlığı ne şekilde etkilediğini ve bu ilişkide lider cinsiyetinin düzenleyici etkisi olup olmadığını araştırmışlardır. Çalışma sonucunda, yardımsever liderliğin, işe adanmışlık üzerinde pozitif ve anlamlı bir etkisi olduğunu, otoriter liderliğin ise, literatürdeki çalışmaların aksine çallşanın işe adanmışlığını etkilemediğini bulmuşlardır. Shu (2015) otoriter ve otantik liderliğin işe adanmışlık üzerindeki etkisinde, iç motivasyonun düzenleyici rolünü araştırmış, otoriter liderliğin işe adanmışlığı negatif şekilde etkilediğini, otantik liderliğin ise işe adanmışlı̆̆ı pozitif şekilde etkilediğini bulmuştur. İç motivasyonun, otantik liderlik ve işe adanmışlık arasındaki ilişkiyi güçlendirdiği, otoriter liderlik ve işe adanmışlık arasındaki ilişkide ise dengeleyici (tampon) vazife gördüğü ortaya çıartılmıştır.

Enwereuzor, vd. (2018) tarafından yapılan çalışmada, dönüşümsel liderlik ve işe adanmışlık arasındaki ilişkide kişinin işe uyumunun (person-job fit) düzenleyici etkisi ölçülmüştür. Bu araştırma sonucuna göre dönüşümsel liderlik ve işe adanmışlık arasında anlamlı ve pozitif bir ilişki belirlenmiş ve bu iki değişken arasındaki ilişkide kişinin işe uyumunun düzenleyici etkisi olduğu görülmüştür. Ayrıca kişinin işe uyumu ve işe adanmışlığı arasında da pozitif ve anlamlı bir ilişki belirlenmiştir. Ghadi vd. (2011)'nin yaptıkları çalışmada, dönüşümsel liderlik ve işe adanmışlık arasında doğrudan bir ilişki olduğu, işte anlam bulmanın bu ilişkide kısmi aracı rolüne sahip olduğu bulunmuş̧tur. Yapılan diğer bir çalışmada, Salanova vd. (2011) dönüşümsel liderlik ve işe adanmışlık arasında doğrudan bir ilişki bulmuşlardır. Zhu, vd. 
(2009) tarafından yapılan bir başka çalışmada ise, takipçi özelliklerinin dönüşümsel liderlik ve işe adanmışlık arasındaki pozitif ilişkiye aracılık ettiği bulunmuştur.

Naidoo ve Martins (2014) örgüt kültürü ve işe adanmışlık arasındaki ilişkiyi araştırmış, örgütsel kültürün tüm boyutlarının işe adanmışlığın tüm boyutları ile pozitif korelasyona sahip olduğunu ortaya çıkarmıştır. Regresyon analizleri sonucunda, liderliğin, yönetim sürecinin, amaç ve hedeflerin, işe adanmışlığı tahmin etmede en yüksek etkiye sahip olduğunu ortaya çıkarmıştır. Çağlar (2012) yaptığı çalışmada, kültür, iklim, yönetim uygulamaları gibi yetkelendirme faktörlerinin, çalışanların işe adanmışlık düzeyini pozitif ve anlamlı şekilde etkilediğini, çalışanların yetkelendirme algısının bu ilişkiye kısmi aracılık ettiğini bulmuştur. Aynı çalışmada, yetkelendirme faktörlerinin, algılanan yetkelendirme ile ilişkisinde, liderlik tarzlarının düzenleyici etkisi olduğu ortaya çıkarılmıştır. Geliştirici liderlik ve otoriter liderlik tarzlarının, her iki faktör (yetkelendirme ve yetkelendirme algısı) ve işe adanmışlık üzerinde anlamlı bir etkisi olduğu belirtilmiştir. Chungtai ve Buckley (2008) yaptıkları çalışmada, işe adanmışlık ve örgütteki güvenin birbirini karşılıklı olarak etkilediğini bulmuştur. Ayrıca bu çalışmada, örgütteki güvenin ülke veya örgüt kültüründen de etkilenebileceği belirtilmiştir.

\section{Araștırma Amacı ve Araștırma Soruları}

Bu araştırmanın amacl; üretim yapan bir işletmede dönüşümsel liderlik ve paternalist liderlik tarzlarının işe adanmışlık üzerindeki etkilerini ve bu ilişkide sıkılık-esnekliğin aracı rolünü incelemektir. Bu amaç ve daha önce bahsedilen teorik açıklamalar çerçevesinde aşağıdaki araştırma soruları oluşturulmuştur:

- Üretim yapan bir işletmede, dönüşümsel liderlik tarzının, çalışanların işe adanmışlık düzeyleri üzerinde etkisi var mıdır?

- Üretim yapan bir işletmede, paternalist liderlik tarzının, çalışanların işe adanmışlık düzeyleri üzerinde etkisi var mıdır?

- Üretim yapan bir işletmede sıkılık-esnekliğin, bu işletmedeki dönüşümsel liderlik tarzları ile çalışanların işe adanmışlık düzeyleri arasındaki ilişkide aracılık rolü bulunmakta mıdır? 
- Üretim yapan bir işletmede sıkılık-esnekliğin, bu işletmedeki paternalist liderlik tarzları ile çalışanların işe adanmışlık düzeyleri arasındaki ilişkide aracilık rolü bulunmakta mıdır?

\section{Araştırma Yöntemi}

Bu araştırma için, geleneksel rekabetçi bir pazarda faaliyet gösteren, yönetim yapısı aile üyelerinden oluşan, yönetim tarzı çalışanların işe adanmasını gerektiren, liderlik tarzı ise çalışanlar üzerinde zaman zaman kontrolün zaman zaman da esnekliğin uygulandığı, çalışanlara bazen otoriter bazen bir aile üyesi gibi davranıldığı gözlem ve mülakatlar sonucunda belirlenen tarzda bir işletme seçilmiştir. Dolayısıyla seçilen bu işletme araştırma değişkenlerinin daha iyi incelenebileceği, hipotezlerin test edilebileceği özelliklere sahiptir.

Araştırmada öncelikle şirketin sahibi ve yönetim kurulu başkanı ile görüşülerek, şirket ile ilgili detaylı bilgi ve yapılacak uygulama ile ilgili izinler alınmıştır. Şirketin merkez ve saha çalışanları ile birlikte toplam 150 çalışanı bulunmaktadır. Tam sayım yöntemine göre, çalışanların tamamına anket uygulanmıştır. Bunlardan 133 kişiden $(\% 88,6)$ anket geri dönüşü olmuştur.

\section{Araştırma Modeli ve Hipotezleri}

Araştırma soruları ve teori çerçevesinde oluşturulan araştırma modeli şekil 1'de görülmektedir. Burada paternalist ve dönüşümsel liderlik bağımsız değişken, işe adanmışlık bağımlı değişken ve sıkılık-esneklik ise aracı değişken olarak belirlenmiştir.

- Hi: Paternalist liderlik, işe adanmışlık düzeyini pozitif ve anlamlı şekilde etkilemektedir.

- $\mathrm{H}_{2}$ : Sıkılık-esneklik, paternalist liderliğin işe adanmışlık üzerindeki etkisine aracılık yapmaktadır.

- H3: Dönüşümsel liderlik, işe adanmışlık düzeyini pozitif ve anlamlı şekilde etkilemektedir.

- H4: Sıkılık-esneklik, dönüşümsel liderliğin işe adanmışlık üzerindeki etkisine aracilık yapmaktadır. 


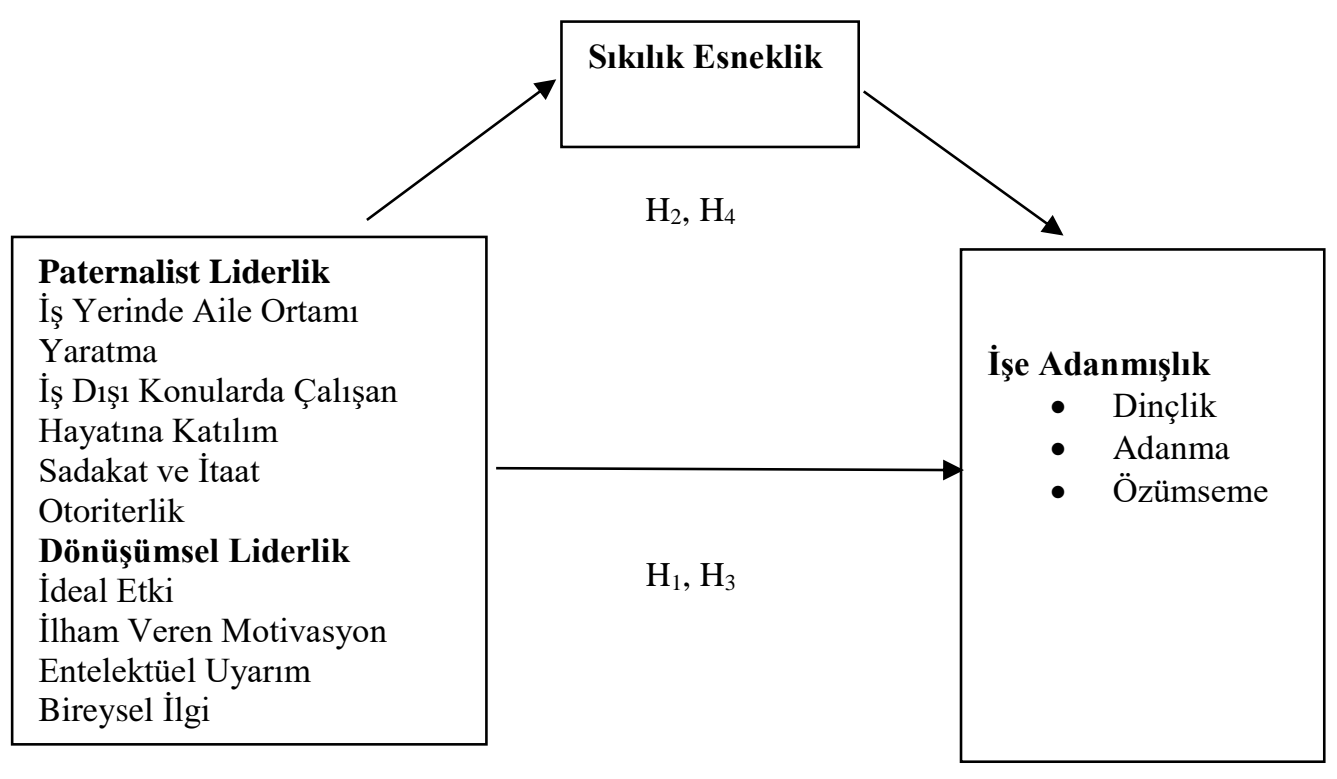

Şekil 1. Araştırma Modeli

\section{Örneklem Yöntemi}

Örneklem, gıda sektöründe üretim yapan bir işletmenin merkezdeki ve sahadaki tüm çalışanlarını kapsamaktadır. Merkez ve sahadaki tüm çalışanlar (toplam 150 kişi) araştırmanın evrenini oluşturmaktadır. Tam sayım yöntemine göre 150 kişinin tamamına, hazırlanan anketler uygulanmıştır. Toplam 133 kişiden geri dönüş olmuştur. Bu veriler $\% 95$ güven aralığı, $\% 5$ hata payı ile analiz edilecektir. Veri seti oluşturulan 133 anket araştırma evrenini temsil gücüne sahiptir. Analiz ve değerlendirmeler bu çerçevede yapılacaktır.

\section{Veri Toplama Yöntemi ve Araçlan}

Araştırma hipotezlerini test edebilmek amaciyla literatürden oluşturulan ölçekler anket formuna dönüştürülerek uygulanmıştır. Anketin ilk kısmında demografik sorular, daha sonraki kısımlarında ise, işe adanmışlık, sıkılık-esneklik, dönüşümsel ve paternalist liderlikle ilgili sorular olmak üzere toplamda 57 soru oluşturulmuştur. 
Paternalist liderlik ölçeği iş yerinde aile ortamı yaratma, iş dışı konularda katılım, sadakat ve itaat, otoriterlik başlıklarında dört alt boyuttan ve toplam 17 sorudan oluşmaktadır. Araştırmada, Aycan vd. (2013) tarafından geliştirilen ölçeğin 10 soruluk kısa versiyonu kullanılmıştır. Değişkenin otoriterlik alt boyutu soruları ise, Cheng, vd. (2004) tarafından geliştirilen ölçeğin Erben ve Ötken (2014) tarafından uyarlandığı çalışmadan alınmıştır. Cevaplarda 7'li likert ölçeği (1-hiçbir zaman, 2-neredeyse hiç, 3-nadiren, 4-bazen,5- sıklıkla,6çok sık, 7-her zaman) kullanılmıştır.

Dönüşümsel liderlik ölçeği, Bass (1985) tarafından ortaya konan daha sonra Avolio (1999) ile birlikte güncelleme yaptıkları çok faktörlü liderlik ölçeğinin (Arslantaş ve Pekdemir, 2007), çeşitli çalışmalarda Türkçe'ye uyarlanmasıyla elde edilen soruların derlenmesiyle elde edilmiştir (Baloğlu, Karadağ ve Gavuz, 2009; Gündüz, 2015; Yolaç, 2011). Araştırmada, Dönüşümsel liderliğin; ideal etki, ilham veren motivasyon, entelektüel uyarım ve bireysel ilgi başliklarında 4 alt boyutta (Bass ve Avolio, 1993) toplamda 20 sorusu bulunmaktadır.

Sıkılık-esneklik ölçeği toplam 5 sorudan oluşmaktadır. Araştırmada, Khandwalla (1976) tarafından geliştirilen, Wasti ve Fiş (2010) tarafından Türkçe'ye uyarlanan ölçek kullanılmıştır (Sakal ve Macit, 2018). Cevaplarda, ölçeğin sağ kısmı esnekliği, sol kısmı sıkılığı temsil eden iki uçlu soruların yer aldığı 7'li ölçek (1-sol sütundaki ifadeyi en iyi yansıtır, 2-sol sütundaki ifadeyi oldukça yansitır. 3-sol sütundaki ifadeyi az yansitır, 4-tam arada bir durumu ifade eder, 5- sağ sütundaki ifadeyi az yansıtır, 6- sağ sütundaki ifadeyi oldukça yansıtır, 7- sağ sütundaki ifadeyi en iyi yansıtır) kullanılmıştır.

Araştırmanın bağımsız değişkeni olan işe adanmışlık ölçeğinin kısa versiyonu; dinçlik, adanma ve özümseme alt boyutlarında ve toplamda 9 sorudan oluşmaktadır. Araştırmada, Schaufeli (2003) tarafından oluşturulan ölçeğin kısa versiyonunun Özkalp ve Meydan (2015) tarafından Türkçe'ye uyarlanmasıyla elde edilen ölçek kullanılmıştır. Cevaplarda 7'li likert ölçeği (1-hiçbir zaman, 2-neredeyse hiç, 3-nadiren,4-bazen,5-sıklıkla,6-çok sık, 7- her zaman) kullanılmıştır.

\section{Bulgular}

Bu bölümde, anket çalışmaları sonucunda elde edilen verilerin analiz sonuçları yer almaktadır. 


\section{Tanımlayıcı İstatistikler}

Tablo 1'de, yaş, cinsiyet eğitim durumu ve kurumda çalışma süresiyle ilgili demografik bilgiler görülmektedir.

Tablo 1. Demografik Bilgiler

\begin{tabular}{|c|c|c|c|c|}
\hline Yaş & Frekans & Yüzde & Geçerli Yüzde & Kümülatif Yüzde \\
\hline $18-24$ & 9 & 6,8 & 6,8 & 6,8 \\
\hline $25-34$ & 45 & 33,8 & 33,8 & 40,6 \\
\hline $35-44$ & 69 & 51,9 & 51,9 & 92,5 \\
\hline $45-54$ & 8 & 6,0 & 6,0 & 98,5 \\
\hline $55-64$ & 2 & 1,5 & 1,5 & 100,0 \\
\hline Toplam & 133 & 100,0 & 100,0 & \\
\hline Cinsiyet & Frekans & Yüzde & Geçerli Yüzde & Kümülatif Yüzde \\
\hline Kadın & 12 & 9,0 & 9,0 & 9,0 \\
\hline Erkek & 121 & 91,0 & 91,0 & 100,0 \\
\hline Toplam & 133 & 100,0 & 100,0 & \\
\hline Eğitim Durumu & Frekans & Yüzde & Geçerli Yüzde & Kümülatif Yüzde \\
\hline İlkokul & 17 & 12,8 & 12,9 & 12,9 \\
\hline Ortaokul & 26 & 19,5 & 19,7 & 32,6 \\
\hline Lise & 63 & 47,4 & 47,7 & 80,3 \\
\hline Önlisans & 9 & 6,8 & 6,8 & 87,1 \\
\hline Lisans & 16 & 12,0 & 12,1 & 99,2 \\
\hline Yükseklisans & 1 & 8 & 8 & 100,0 \\
\hline Toplam & 132 & 99,2 & 100,0 & \\
\hline Değerlendirme dışı & 1 & 8 & 8 & \\
\hline Toplam & 133 & 100,0 & & \\
\hline Çalışma Süresi & Frekans & Yüzde & Geçerli Yüzde & Kümülatif Yüzde \\
\hline $0-1$ & 28 & 21,1 & 21,5 & 21,5 \\
\hline $2-3$ & 13 & 9,8 & 10 & 31,5 \\
\hline $4-5$ & 33 & 24,8 & 25,4 & 56,9 \\
\hline $6-10$ & 38 & 28,6 & 29,2 & 86,2 \\
\hline $10+$ & 18 & 13,5 & 13,8 & 100 \\
\hline Toplam & 130 & 97,7 & 100 & \\
\hline Değerlendirme dişı & 3 & 2,3 & & \\
\hline Toplam & 133 & 100 & & \\
\hline
\end{tabular}

Tablo 1'deki demografik bilgiler incelendiğinde çalışanların büyük çoğunluğunun (\%85,7) 25 ve 44 yaş aralığında olduğu görülmektedir. Cinsiyet dağılımı incelendiğinde, çalışanların büyük çoğunluğunun (\%91) erkek olduğu dikkat çekmektedir. Çalışanların \%47'sinin lise mezunu, \%32'sinin or- 
taokul ve altı, yaklaşık \% 20'sinin ise lise üstü eğitime sahip olduğu belirlenmiştir. Katılımcıların kurumda çalışma süresi incelendiğinde \%21'inin çalışma süresinin 1 yıl ve altında olduğu, \%10'unun 2 ve 3 yıl arasında olduğu, $\% 25$ 'inin 4 ve 5 yıl arasında olduğu, \%42'sinin de 6 yıl ve üzeri olduğu görülmektedir.

Tablo 2'de, araştırma değişkenlerine ilişkin tanımlayıcı istatistiksel değerler görülmektedir. Araştırmanın, işe adanmışlık, dönüşümsel ve paternalist liderlik olarak üç temel değişkeni ve sıkılık-esneklik olarak bir aracı değişkeni bulunmaktadır. İşe adanmışlık değişkeni altında dinçlik, adanmışlık ve özümseme olarak üç alt değişken bulunmaktadır. Dönüşümsel liderlik değişkeni altında, ideal etki, ilham verici motivasyon, entelektüel uyarım ve bireysel ilgi olarak dört alt değişken bulunmaktadır. Paternalist liderlik değişkeni altında, aile ortamı yaratma, iş dışı konularda katılım, sadakat ve itaat ve otoriterlik olarak dört alt değişken bulunmaktadır. Sıkılık-esneklik değişkeni ise tek boyutta incelenmiştir.

Tablo 2 detaylı olarak incelendiğinde, $7^{\prime}$ li likert ölçeğine göre değişkenlerin ortalamalarının 4,35 ile 5,72 arasında olduğu görülmektedir. Ayrıca değişkenlere ilişkin çarpıklık ve basıklık değerleri, verilerin normal dağılıma sahip olduğunu göstermektedir.

Tablo 2. Değişkenlere İlişkin Tanımlayıcı İstatistikler

\begin{tabular}{llllllll}
\hline & \multicolumn{7}{c}{ Std. } \\
Değişkenler ve Alt Boyutları & Sayı & Ortalama & Sapma & Çarpıklık & Basıklık & Min. & Maks. \\
\hline Paternalist Liderlik & 133 & 4,89 & 1,43 & $-0,49$ & 0,05 & 1,00 & 7,00 \\
Aile Ortamı & 133 & 5,45 & 1,60 & $-1,10$ & 0,34 & 1,00 & 7,00 \\
İş Dışı Konular & 133 & 5,06 & 1,85 & $-0,76$ & $-0,52$ & 1,00 & 7,00 \\
Sadakat & 133 & 5,42 & 1,61 & $-1,07$ & 0,45 & 1,00 & 7,00 \\
Otoriterlik & 133 & 4,35 & 1,80 & $-0,05$ & $-0,97$ & 1,00 & 7,00 \\
Dönüşümsel Liderlik & 132 & 5,48 & 1,54 & $-1,02$ & 0,03 & 1,28 & 7,00 \\
İdeal Etki & 133 & 5,42 & 1,53 & $-0,86$ & $-0,19$ & 1,33 & 7,00 \\
İlham Verici Motivasyon & 133 & 5,61 & 1,64 & $-1,17$ & 0,26 & 1,00 & 7,00 \\
Entelektüel Uyarım & 133 & 5,47 & 1,66 & $-1,11$ & 0,33 & 1,00 & 7,00 \\
Bireysel İlgi & 133 & 5,48 & 1,66 & $-1,07$ & 0,12 & 1,00 & 7,00 \\
Sıkılik-Esneklik & 133 & 4,48 & 1,88 & $-0,09$ & $-1,19$ & 1,00 & 7,00 \\
İşe Adanmışlik & 132 & 5,62 & 1,31 & $-0,80$ & $-0,36$ & 2,11 & 7,00 \\
Dinçlik & 132 & 5,72 & 1,48 & $-1,00$ & $-0,18$ & 2,00 & 7,00 \\
Adanmışlik & 132 & 5,66 & 1,49 & $-0,94$ & $-0,12$ & 1,00 & 7,00 \\
Özümseme & 132 & 5,45 & 1,43 & $-0,64$ & $-0,62$ & 2,00 & 7,00 \\
\hline
\end{tabular}


Tablo 2'de değişkenlerin ortalamaları incelendiğinde, paternalist liderliğin otoriterlik alt boyutu hariç diğer alt değişkenlerin ortalamasının 5'in üzerinde olduğu dikkat çekmektedir. Sıkılık-esneklik değişkeninin ortalamasının 4,48 olduğu, bu da katılımcıların örgüt kurallarını daha esnek olarak algıladıklarını göstermektedir.

\section{Güvenilirlik ve Geçerlilik Analizleri}

Anketin güvenilirlik analizi için Cronbach alfa katsayısı kullanılmış, geçerlilik analizi için de KMO ve Bartlett testleri ile faktör analizi yapılmıştır.

\section{Güvenilirlik Analizi}

Araştırma değişkenlerine ilişkin Cronbach alfa ve ortalama değerler tablo 3'te gösterilmektedir.

\section{Tablo 3. Güvenilirlik Analizi}

\begin{tabular}{lll}
\hline Değişken & Ortalama & Cronbach Alfa \\
\hline Paternalist liderlik & 4,89 & 0,87 \\
\hline Paternalist liderlik - aile ortamı yaratma & 5,45 & 0,82 \\
Paternalist liderlik - iş dışı konularda katılım & 5,06 & 0,90 \\
Paternalist liderlik - sadakat ve itaat & 5,42 & 0,90 \\
Paternalist liderlik - otoriterlik & 4,35 & 0,91 \\
\hline Dönüşümsel liderlik & 5,48 & 0,94 \\
\hline Dönüşümsel liderlik - ideal etki & 5,42 & 0,93 \\
Dönüşümsel liderlik - ilham veren motivasyon & 5,61 & 0,94 \\
Dönüşümsel liderlik - entelektüel uyarım & 5,47 & 0,95 \\
Dönüşümsel liderlik - bireysel destek & 5,48 & 0,91 \\
\hline Sıkılık-esneklik & 4,48 & 0,86 \\
\hline İse adanmışlık & 5,62 & 0,93 \\
\hline İșe adanmışlık - dinçlik & 5,72 & 0,92 \\
İșe adanmışlık - adanma & 5,66 & 0,91 \\
İşe adanmıslık - özümseme & 5,45 & 0,78 \\
\hline
\end{tabular}

Tablo 3 incelendiğinde, değişkenlerin güvenilirlik değerlerinin 0,78 ile 0,95 arasında olduğu görülmektedir. Buna göre tüm ölçeklerin her bir alt boyutunun yeterli güvenilirlik değerine sahip olduğu belirlenmiştir. 
Değişkenlerin ortalamalarına bakıldığında iki değişken hariç ortalamaların 5'in üzerinde olduğu görülmektedir. Hem dönüşümsel hem de paternalist liderlik tarzı da ortalamanın üzerinde çıkmıştır. Paternalist liderliğin otoriterlik alt boyutunun ortalamasının 4,35, sıkllık-esneklik değişkeninin ortalamasının ise 4,48 olduğu tespit edilmiştir. Buna göre, firma örgüt kültürünün esnekliğe daha yakın olduğu söylenebilir. Bunun yanında, çalışanların paternalist liderliğe ilişkin otoriterlik algılarına bakıldığında, firma içerisindeki liderlik tarzının 4,35 ortalama ile otoriterliği de içerdiği görülmektedir. Yönetim kültürümüzde yapılan araştırmalarda genellikle paternalist liderliğin otoriterlik haricindeki üç boyutu kullanılmaktadır. Ancak bu çalışmada yaygın olarak kullanılan üç alt boyutun yanında otoriterlik de kullanılmıştır. $\mathrm{Bu}$ çalışmada otoriterlik alt boyutunun kullanılması paternalist liderliğin daha iyi yorumlanmasına katkı sağlayacaktır.

\section{Faktör Analizi}

Faktör analizi için öncelikle KMO ve Bartlett testi kullanılmıştır. Yapılan analizlerde elde edilen KMO katsayıları aşağıdaki gibi çıkmıştır. Bu katsayıların 0,60' dan yüksek olmasından dolayı ölçeklerin faktör analizinin yapılabilmesi uygun olmuştur. Paternalist liderliğin faktör analizi sonuçları aşağıdaki tablo 4'te görülmektedir.

Tablo 4'te paternalist liderlik ölçeğinin dört alt faktörde toplandığı görülmektedir. Aile ortamı yaratma alt boyutunda 2 . sorunun faktör yükü 0,50 'nin altında olduğundan dolayı bu soru analizlere dahil edilmemiştir. Öz değeri 1'in üzerinde olan dört faktör toplam varyansın \% 50,37'sini açılamaktadır. Birinci faktör 4 maddeden oluşmakta ve toplam varyansın \%67,31'ini açılamaktadır. İkinci faktör 3 maddeden oluşmakta ve toplam varyansın \%83,81'ini açıklamaktadır. Üçüncü faktör 3 maddeden oluşmakta ve toplam varyansın \%81,97'sini açıklamaktadır. Dördüncü faktör 7 maddeden oluşmakta ve toplam varyansın \%64,63'ünü açklamaktadır. 
Paternalist ve Dönüşümsel Liderlik Tarzlarının İşe Adanmışlık Üzerindeki Etkisinde, SıkılıkEsneklik Değişkeninin Aracılık Rolü

Tablo 4. Paternalist Liderlik Ölçeği Faktör Yükleri

\begin{tabular}{|c|c|c|c|}
\hline \multirow[b]{2}{*}{ I. Faktör: Aile Ortamı Yaratma } & \multirow[t]{2}{*}{$\begin{array}{r}\text { Faktör } \\
\text { Yükü }\end{array}$} & \multicolumn{2}{|c|}{$\begin{array}{r}\text { Öz Açılanan } \\
\text { değer Varyans \% }\end{array}$} \\
\hline & & 2,692 & $2 \quad 67,310$ \\
\hline $\begin{array}{l}\text { İdeal bir lider/yönetici çalıșanlarına karșı, bir aile büyüüü (baba/anne } \\
\text { veya ağabey/abla) gibi davranır. }\end{array}$ & 897 & & \\
\hline İdeal bir lider/yönetici çalıșanlarına bir aile büyügü gibi ögŭit verir. & ,465 & & \\
\hline İdeal bir lider/yönetici isyerinde aile ortamı yaratmaya önem verir & , 928 & & \\
\hline $\begin{array}{l}\text { İdeal bir lider/yönetici bir ebeveynin çocugundan sorumlu olması gibi, } \\
\text { her çalıșanından kendini sorumlu hisseder. }\end{array}$ & ,900 & & \\
\hline II. Faktör: İş Dışı Konularda Katılım & & 2,514 & 83,814 \\
\hline $\begin{array}{l}\text { İdeal bir lider/yönetici ihtiyaçları olduğ zaman, çalıșanlarına is, dıșı } \\
\text { konularda (örn., ev kurma, çocuk okutma saglık vs.) yardım etmeye } \\
\text { hazırdır. }\end{array}$ & ,911 & & \\
\hline $\begin{array}{l}\text { İdeal bir lider/yönetici çalıșanlarının özel günlerine (örn., nikah, cenaze, } \\
\text { mezuniyet vs.) katılır. }\end{array}$ & 914 & & \\
\hline $\begin{array}{l}\text { İdeal bir lider/yönetici çalıșanlardan birinin özel hayatında yașadı̆ı̆ } \\
\text { problemlerde (örn; eșlerarası problemlerde) arabuluculuk yapmaya } \\
\text { hazırdır. }\end{array}$ & ,922 & & \\
\hline III. Faktör: Sadakat ve İtaat & & 2,459 & 81,965 \\
\hline $\begin{array}{l}\text { İdeal bir lider/yönetici çalıșanlarında sadakate, performansa } \\
\text { verdiğ̈nden daha fazla önem verir. }\end{array}$ & 899 & & \\
\hline \multicolumn{4}{|l|}{ Tablo 4'ün devamı } \\
\hline $\begin{array}{l}\text { İdeal bir lider/yönetici çalıs,anlarına gösterdiğ ilgi ve alakaya karşıllık, } \\
\text { onlardan baghllık ve sadakat bekler. }\end{array}$ & ,914 & & \\
\hline $\begin{array}{l}\text { İdeal bir lider/yönetici çalıșanları için neyin en iyi oldugünu } \\
\text { bildiğne inanır. }\end{array}$ & ,903 & & \\
\hline IV.Faktör: Otoriterlik & & 4,524 & 64,633 \\
\hline Yöneticim önemli veya önemsiz șirketteki buitün kararları verir. & 665 & & \\
\hline Yöneticim görevlerimizi yerine getiremedigimizde bizi azarlar. & 849 & & \\
\hline Yöneticim astlarına sıkı bir disiplin uygular. & 824 & & \\
\hline Yöneticim toplantılarda her zaman en son kararı verir. & ,715 & & \\
\hline Yöneticim ile çalıșırken kendimi baskı altında hissederim. & 856 & & \\
\hline $\begin{array}{l}\text { Yöneticim çalıșanların gözü önünde her zaman emreder șekilde } \\
\text { davranır. }\end{array}$ & 864 & & \\
\hline $\begin{array}{l}\text { Yöneticim ișleri yapmak için onun kurallarına uymamız gerekir. } \\
\text { Aksi takdirde bizi cezalandırır. }\end{array}$ & 832 & & \\
\hline $\begin{array}{l}\text { Faktör çlkarma metodu: Temel bileşenler analizi; Döndürme metodu: Varimax } \\
\text { Kaiser-Meyer-Olkin Örneklem Yeterliliği: \% 91,7 } \\
\text { Bartlett's Küresellik Testi için Ki-Kare: 1838,809 p<0,05 } \\
\text { Açılanan toplam varyans: \%50,371; Ölçeğin tamamı için güvenirlik katsayıs }\end{array}$ & sl: 0,869 & & \\
\hline
\end{tabular}

Dönüşümsel liderliğin faktör analizi sonuçları aşağıdaki tablo 5'te görülmektedir. 
Tablo 5. Dönüşümsel Liderlik Ölçeği Faktör Yükleri

\begin{tabular}{|c|c|c|c|}
\hline & $\begin{array}{r}\text { Faktör } \\
\text { Yükü }\end{array}$ & $\begin{array}{r}\text { Öz } \\
\text { değer }\end{array}$ & $\begin{array}{l}\text { Açıklanan } \\
\text { Varyans \% }\end{array}$ \\
\hline I. Faktör: İdeal Etki & & 5,004 & 62,546 \\
\hline Lider, kendisiyle birlikte olmaktan gurur duyulmasını sağlar. & ,817 & & \\
\hline Grubun iyiliği liderin kendi önceliklerinden önemlidir. & ,884 & & \\
\hline Lider, iyi bir grup olmak için kendi ilgilerinin ötesine geçer. & ,852 & & \\
\hline Liderin tavırları çalışanlara güç ve güven hissi verir. & ,880 & & \\
\hline Lider, çalışanların en çok önem verdiği değerler ve inançlar hakkında kouşur. & 716 & & \\
\hline Lider , güçlü bir amaca sahip olmanın önemini vurgular. & 868 & & \\
\hline Lider, kararlar alınırken bunların manevi ve etik sonuçlarını dikkate alır. & 809 & & \\
\hline $\begin{array}{l}\text { Lider, çalışanlar arasında ortak bir görev duygusu oluşturmanın önemini } \\
\text { vurgular. }\end{array}$ & ,363 & & \\
\hline II. Faktör: İlham Veren Motivasyon & & 3,405 & 85,134 \\
\hline Lider, gelecek hakkında umutludur ve iyimser konuşur. & ,900 & & \\
\hline Lider, başarı elde edilmesi gereken durumlarda coşkuyla konuşur. & ,917 & & \\
\hline Lider, işletmenin vizyonunu vurgular. & 942 & & \\
\hline Lider, hedeflere ulaşabileceğine dair çalsşanlara olan güvenini belli eder. & ,930 & & \\
\hline III. Faktör: Entelektüel Uyarım & & 3,466 & 86,638 \\
\hline $\begin{array}{l}\text { Lider, işletme ile ilgili kritik kararların uygunluğunu sorgular ve bunları yeniden } \\
\text { gözden geçirir. }\end{array}$ & ,926 & & \\
\hline Lider, sorunları çözmek için farklı bakış açılarına başvurur. & ,928 & & \\
\hline Lider, çalışanların sorunları farklı açılardan ele almasını sağlar. & ,926 & & \\
\hline $\begin{array}{l}\text { Lider, çalışanların görevlerini tamamlamaları konusunda yeni yollar aramayı } \\
\text { önerir. }\end{array}$ & ,944 & & \\
\hline IV. Faktör: Bireysel İlgi & & 3,173 & 79,318 \\
\hline Lider, çalışanları yetiştirmeye ve yönlendirmeye dönük zaman ayırır. & 921 & & \\
\hline Lider, çalışanlara yalnızca ekibin bir üyesi olarak değil, birer birey olarak davranır. & ,920 & & \\
\hline $\begin{array}{l}\text { Lider, çalışanların birbirinden bağımsız ve farklı ihtiyaç, yetenek ve isteklere sahip } \\
\text { olduğunun farkındadır. }\end{array}$ & 893 & & \\
\hline Lider, çalışanların güçlü yönlerini geliştirmeleri konusunda onlara yardımcı olur. & ,825 & & \\
\hline \multicolumn{4}{|l|}{ Faktör çıkarma metodu: Temel bileşenler analizi; Döndürme metodu: Varimax } \\
\hline \multicolumn{4}{|l|}{ Kaiser-Meyer-Olkin Örneklem Yeterlilĭ̆i: \% 94,3 } \\
\hline \multicolumn{4}{|l|}{ Bartlett's Küresellik Testi için Ki-Kare: 2653,181 p<0,05 } \\
\hline Açıklanan toplam varyans: \%68,137; Ölçeğin tamamı için güvenirlik katsayısı: 0,93 & & & \\
\hline
\end{tabular}

Tablo 5'te dönüşümsel liderlik ölçeğinin teoride de olduğu gibi dört alt faktörde toplandığı görülmektedir. İdeal etki boyutunda 8. sorunun faktör yükü 0,50'nin altında olduğundan dolayı bu soru analizlere dahil edilmemiştir. Öz değeri 1'in üzerinde olan dört faktör toplam varyansın \% 68,14'ünü açıklamaktadır. Birinci faktör 8 maddeden oluşmakta ve toplam varyansın \%62,55'ini açklamaktadır. İkinci faktör 4 maddeden oluşmakta ve toplam varyansın \%85,13'ünü açıklamaktadır. Üçüncü faktör 4 maddeden oluşmakta ve toplam varyansın \%86,64'ünü açıklamaktadır. Dördüncü faktör 4 
Paternalist ve Dönüşümsel Liderlik Tarzlarının İşe Adanmışlık Üzerindeki Etkisinde, SıkılıkEsneklik Değişkeninin Aracılık Rolü

maddeden oluşmakta ve toplam varyansın \%79,32' sini açıklamaktadır. Aşağıdaki tablo 5'te sıkılık-esneklik ölçeğine ilişkin faktör analizi sonucu görülmektedir.

\section{Tablo 6. Sıkılık-Esneklik Ölçeği Faktör Yükleri}

\begin{tabular}{|c|c|c|c|}
\hline & $\begin{array}{r}\text { Faktör } \\
\text { Yükü }\end{array}$ & $\begin{array}{r}\text { Öz } \\
\text { değer }\end{array}$ & $\begin{array}{l}\text { Açıklanan } \\
\text { Varyans \% }\end{array}$ \\
\hline I. Faktör: Sıkılık-Esneklik & & 3,248 & 64,963 \\
\hline $\begin{array}{l}\text { SE1. soru: 1puan- Karar alma sürecinde, en çok söz hakkının, yönetim kade- } \\
\text { melerine düşmesine büyük önem verilir.7 puan- Karar alma sürecinde, hiye- } \\
\text { rarşik yapıyı ihlal edecek bile olsa, en çok söz hakkının konunun uzmanlarına } \\
\text { verilmesine yönelik güçlü bir eğilim vardır. }\end{array}$ & ,766 & & \\
\hline $\begin{array}{l}\text { SE2. soru: } 1 \text { puan- İş tanımları belirli ve özel (spesifik) dir. } 7 \text { puan- İş tanımları } \\
\text { esnek ve geneldir. }\end{array}$ & ,748 & & \\
\hline $\begin{array}{l}\text { SE3. soru: } 1 \text { puan- İş koşullarındaki değişimlere ayak uydurabilmek için, de- } \\
\text { nenmiș ve başarılı olmuş yönetim prensiplerinin uygulanmasına büyük önem } \\
\text { verilir. } 7 \text { puan- Değişen koşullara uyum sağlamada, başarılı olsa dahi geçmiş } \\
\text { uygulamalar fazlaca dikkate alınmaz. Özgün ve farklı davranılmasına büyük } \\
\text { önem verilir. }\end{array}$ & 854 & & \\
\hline $\begin{array}{l}\text { SE4. soru: } 1 \text { puan- İletişim, iyice yapılandırılmıs kanallar aracllı̆ıyla yürütü- } \\
\text { lür. Önemli finansal ve operasyonel bilgilere erişim çok sınırlıdır. } 7 \text { puan- İle- } \\
\text { tişim kanalları çok açıktır. Önemli finansal ve operasyonel bilgiler şirket içeri- } \\
\text { sinde oldukça serbest bir şekilde dolaşır. }\end{array}$ & 887 & & \\
\hline $\begin{array}{l}\text { SE5. soru: } 1 \text { puan- Standart bir yöneticilik tarzının uygulanmasında ısrar edi- } \\
\text { lir. } 7 \text { puan- Yöneticilik tarzlarının, geniş bir yelpazede farklılaşmasına izin ve- } \\
\text { rilir. }\end{array}$ & ,765 & & \\
\hline $\begin{array}{l}\text { Döndürme metodu: Varimax } \\
\text { Kaiser-Meyer-Olkin Örneklem Yeterliliği: \% 86,0 } \\
\text { Bartlett's Küresellik Testi için Ki-Kare: 284,514 p<0,05 } \\
\text { Açlklanan toplam varyans: \%64,963; Ölçeğin tamamı için güvenirlik katsayıs }\end{array}$ & & & \\
\hline
\end{tabular}

Tablo 6'te sıkllık-esneklik ölçeğinin teoride de olduğu gibi tek faktörde toplandığ1 görülmektedir. Özdeğeri 1'in üzerinde olan ve tek faktörde toplanmış olan 5 madde toplam varyansın \% 64,96'sını açıklamaktadır. Aşağıda tablo $7^{\prime}$ de ise işe adanmışlık ölçeğinin faktör yükleri, öz değer ve açıklanan varyansları görülmektedir. 
Tablo 7. İşe Adanmışlık Ölçeği Faktör Yükleri

\begin{tabular}{|c|c|c|c|}
\hline & $\begin{array}{l}\text { Faktör } \\
\text { Yükü }\end{array}$ & $\begin{array}{l}\text { Öz } \\
\text { değer }\end{array}$ & $\begin{array}{l}\text { Açıklanan } \\
\text { Varyans \% }\end{array}$ \\
\hline I. Faktör: Dinçlik & & 2,575 & 85,826 \\
\hline D1.Ișimi yaparken kendimi çok enerjik hissederim. & ,950 & & \\
\hline D2.Ișimi yaparken kendimi gü̈çü ve dinç hissederim & ,937 & & \\
\hline D3.Sabah uyandığmda ișe gitme isteğ duyuyorum & 891 & & \\
\hline II. Faktör: Adanmışlık & & 2,558 & 85,260 \\
\hline A1.Ișim bana coșku veriyor. & 932 & & \\
\hline A2.Ișim bana ilham veriyor. & ,940 & & \\
\hline A3.Yaptığm ișten gurur duyuyorum. & 897 & & \\
\hline III. Faktör: Özümseme & & 2,087 & 69,582 \\
\hline O1.Yogun bir șekilde çalışırken kendimi mutlu hissediyorum. & 772 & & \\
\hline O2.Ișe gömuilmüș durumdayım. & 880 & & \\
\hline O3.Calış̧rken kendimden geçiyorum. & ,847 & & \\
\hline \multicolumn{4}{|c|}{ Faktör çıkarma metodu: Temel bileşenler analizi; Döndürme metodu: Varimax } \\
\hline \multicolumn{4}{|c|}{ Kaiser-Meyer-Olkin Örneklem Yeterliliği: \% 89,2 } \\
\hline \multicolumn{4}{|l|}{ Bartlett's Küresellik Testi için Ki-Kare: 984,088 p<0,05 } \\
\hline Açıklanan toplam varyans: \%.66,747; Ölçeğin tamamı için güve & ylsl: 0,931 & & \\
\hline
\end{tabular}

Tablo 7'de işe adanmışlık ölçeğinin teoride de olduğu gibi üç alt faktörde toplandığı görülmektedir. 9 madde ve öz değeri 1'in üzerinde olan üç faktör toplam varyansın \% 67,75'ini açıklamaktadır. Birinci faktör 3 maddeden oluşmakta ve toplam varyansın \%85,82'sini açılamaktadır. İkinci faktör 3 maddeden oluşmakta ve toplam varyansın \%85,26'sını açıklamaktadır. Üçüncü faktör 3 maddeden oluşmakta ve toplam varyansın \%69,58'ini açılamaktadir.

\section{Paternalist Liderlik ve Dönüşü̈msel Liderliğin İşe Adanmışlık Üzerindeki Et- kisinde Sıkılık-Esnekliğin Aracı Rolü ile ilgili Hipotez Testleri}

Bu bölümde, paternalist ve dönüşümsel liderliğin işe adanmışlık üzerindeki etkisi ve sıkılık-esnekliğin bu etki üzerindeki aracllık rolü araştırılmıştır. Bağımsız değişken olarak paternalist liderlik ve dönüşümsel liderlik; aracı değişken olarak sıkılık-esneklik; bağımlı değişken olarak da işe adanmışlık kullanılmıştır. Yapılan analizlerin tamamında \%5'lik belirlilik düzeyinde çalışılmıştır. Araştırma hipotezleri şu şekildedir:

- H1: Paternalist liderlik, işe adanma düzeyini anlaml ve pozitif şekilde etkilemektedir. 
- $\quad \mathrm{H}_{2}$ : Sıkılık-esneklik, paternalist liderliğin işe adanmışlı üzerindeki etkisine aracılık yapmaktadır.

- H3: Dönüşümsel liderlik, işe adanma düzeyini pozitif ve anlamlı şekilde etkilemektedir.

- H4: Sıkılık-esneklik, dönüşümsel liderliğin işe adanmışlık üzerindeki etkisine aracılık yapmaktadır.

Yapılan basit doğrusal regresyon analizi ile $\mathrm{H}_{1}$ hipotezi test edilmiştir. Analiz sonucu tablo 8'de görülmektedir.

Tablo 8. Paternalist Liderliğin, İşe Adanmışlık Üzerindeki Etkisine Yönelik Basit Doğrusal Regresyon Analizi

\begin{tabular}{|c|c|c|c|c|c|c|}
\hline \multicolumn{7}{|c|}{ Paternalist Liderlik ile İşe Adanma Analizi } \\
\hline \multirow{2}{*}{\multicolumn{2}{|c|}{ Model }} & \multicolumn{2}{|c|}{$\begin{array}{l}\text { Standardize } \\
\text { edilmemiş katsayılar }\end{array}$} & \multirow{2}{*}{$\begin{array}{l}\text { Standardize } \\
\text { katsayılar } \\
\text { Beta } \\
\end{array}$} & \multirow[t]{2}{*}{$\mathrm{T}$} & \multirow[t]{2}{*}{$\mathrm{p}$} \\
\hline & & $\mathrm{B}$ & Std. Hata & & & \\
\hline \multirow{2}{*}{1} & Sabit & 3,263 & 0,362 & & 9,005 & , 000 \\
\hline & Paternalist liderlik & 0,478 & 0,071 & 0,509 & 6,745 & 000 \\
\hline
\end{tabular}

Bağımlı Değişken: İşe Adanma Bağımsız Değişken: Paternalist Liderlik R: 0,509; R²: 0,259; Düzeltilmiş R²: 0,254; Model için F: 45,489

Tablo 8 incelendiğinde, Paternalist liderliğin işe adanma üzerinde anlamlı etkisinin olduğu görülmüştür $(\beta=0,509, p<0,05)$. Paternalist liderliğin işe adanma toplam varyansının \%25.4'ünü açılandığı bulunmuştur.

Sıkılık-esnekliğin, paternalist liderliğin işe adanmışlık üzerindeki etkisindeki aracılık rolünü test etmek için, tablo 9, 10 ve 11'deki analizler yapılmıştır.

Tablo 9. Paternalist Liderliğin, Sıkılık-Esneklik Üzerindeki Etkisine Yönelik Basit Doğrusal Regresyon Analizi

\begin{tabular}{|c|c|c|c|c|c|c|}
\hline \multicolumn{7}{|c|}{ Paternalist Liderlik ile Sıkılık-Esneklik Analizi } \\
\hline \multirow{3}{*}{\multicolumn{2}{|c|}{ Model }} & \multirow{2}{*}{\multicolumn{2}{|c|}{$\begin{array}{l}\text { Standardize } \\
\text { edilmemiş katsayılar }\end{array}$}} & Standardize & $\mathrm{T}$ & $\mathrm{p}$ \\
\hline & & & & katsayılar & & \\
\hline & & $\mathrm{B}$ & Std. Hata & Beta & & \\
\hline \multirow{2}{*}{1} & Sabit & 1,369 & 0,514 & & 2,665 & 0,009 \\
\hline & Paternalist liderlik & 0,637 & 0,101 & 0,483 & 6,316 & 0,000 \\
\hline
\end{tabular}

Bağımlı Değişken: Sıkılık-Esneklik Bağımsız Değişken: Paternalist Liderlik

R: 0,483; R2: 0,233; Düzeltilmiş R2: 0,228; Model için F: 39,897 
Tablo 8 incelendiğinde, paternalist liderliğin sıkılık-esneklik üzerinde anlamlı etkisinin olduğu görülmüştür $(\beta=0,483 p<0,05)$. Paternalist liderliğin s1kılık-esneklik toplam varyansının \%22.8' ini açıklandığı bulunmuştur.

Tablo 10. Sıkılık-Esnekliğin, İşe Adanmışlık Üzerindeki Etkisine Yönelik Basit Doğrusal Regresyon Analizi

\begin{tabular}{|c|c|c|c|c|c|c|}
\hline \multicolumn{7}{|c|}{ Sıkılık-Esneklik ile İşe Adanma Analizi } \\
\hline \multirow{3}{*}{\multicolumn{2}{|c|}{ Model }} & \multirow{2}{*}{\multicolumn{2}{|c|}{$\begin{array}{l}\text { Standardize } \\
\text { edilmemiş katsayılar }\end{array}$}} & Standardize & $\mathrm{T}$ & $p$ \\
\hline & & & & katsayılar & & \\
\hline & & $\mathrm{B}$ & Std. Hata & Beta & & \\
\hline \multirow{2}{*}{1} & Sabit & 4,291 & ,272 & & 15,751 &, 000 \\
\hline & Sikılık-Esneklik & ,294 & ,056 & 419 & 5,259 & ,000 \\
\hline
\end{tabular}

Bağımlı Değişken: İşe Adanma Bağımsız Değişken: Sıkılık-Esneklik

R: 0,419; R2: 0,175; Düzeltilmiş R2: 0,169; Model için F: 27,659

Tablo 10 incelendiğinde, sskılık-esnekliğin işe adanma üzerinde anlamlı etkisinin olduğu görülmüştür $(\beta=0,419$ p <0,05). Sıkılık-esnekliğin işe adanma toplam varyansının \%16.9'unu açıklandığı bulunmuştur.

Tablo 11. Paternalist Liderlik ve Sikılık-Esnekliğin, İşe Adanmışlık Üzerindeki Etkisine Yönelik Hiyerarşik Regresyon Analizi (Aracılık Testi)

\begin{tabular}{|c|c|c|c|c|c|c|}
\hline \multicolumn{7}{|c|}{ Paternalist Liderlik ve Sıkılık-Esneklik ile İşe Adanma Analizi } \\
\hline \multirow{3}{*}{\multicolumn{2}{|c|}{ Model }} & \multirow{2}{*}{\multicolumn{2}{|c|}{$\begin{array}{l}\text { Standardize } \\
\text { edilmemiş katsayılar }\end{array}$}} & \multirow{3}{*}{$\begin{array}{l}\begin{array}{l}\text { Standardize } \\
\text { katsayılar }\end{array} \\
\text { Beta } \\
\end{array}$} & \multirow[t]{3}{*}{$\mathrm{T}$} & \multirow[t]{3}{*}{$\mathrm{p}$} \\
\hline & & & & & & \\
\hline & & B & Std. Hata & & & \\
\hline \multirow[t]{3}{*}{1} & Sabit & 3,034 & 0,363 & & 8,359 & 000 \\
\hline & Paternalist Liderlik & 0,376 & 0,078 & 0,401 & 4,807 & 000 \\
\hline & S1kılık-Esneklik & 0,162 & 0,058 & 0,231 & 2,767 & ,006 \\
\hline
\end{tabular}

Bağımlı Değişken: İ̧̧e Adanmışlık Bağımsız Değişken: Paternalist Liderlik ve Sıkılık-Esneklik R: 0,548; R2: 0,301; Düzeltilmiş R2: 0,290; Model için F: 27,737

Tablo 11 incelendiğinde, paternalist liderlik ve sıkılık-esnekliğin birlikte işe adanma üzerinde anlamlı etkisinin olduğu görülmüştür (Paternalist liderlik $\beta=0,401$, sıkılık-esneklik $\beta=0,231, p<0,05)$. Paternalist liderlik ve sikılık-esnekliğin birlikte işe adanma toplam varyansının \%29'unu açıkladığı bulunmuştur. Bu durumda, sıkılık-esnekliğin, paternalist liderliğin işe adanmışlık üzerindeki etkisinde kısmi aracılık rolü olduğu söylenebilir. Bu aracılık etkisinin anlamlı olup olmadığını görmek için Tablo 12' deki Sobel testi yapılmıştir. 
Tablo 12. Sobel Testi-Paternalist Liderliğin İşe Adanmışlık Üzerindeki Etkisinde SıkılıkEsnekliğin Aracı Rolii

\begin{tabular}{llllll}
\hline Girdi & & Test & Test İstatistikleri & Std Sapma & p-değeri \\
\hline a & 0,637 & Sobel & 4,03497836 & 0,04641363 & 0,00005461 \\
b & 0,294 & Aroian & 4,00534816 & 0,04675698 & 0,00006193 \\
$\mathrm{Sa}$ & 0,101 & Goodman & 4,06527602 & 0,04606772 & 0,00004798 \\
$\mathrm{Sb}$ & 0,056 & & & & \\
\hline
\end{tabular}

Sobel testi ile sıkılık-esnekliğin kısmi aracllık etkisi teyit edilmiştir. Alt boyutlar arasında yapılan analizde ise sıkılık-esnekliğin yalnızca otoriter liderlik alt boyutunun işe adanmışlı̆̆ı özümseme alt boyutu üzerindeki etkisi üzerindeki aracı rolü teyit edilememiştir. Paternalist liderliğin ve işe adanmanın alt boyutları arasındaki ilişkide de sıkılık-esnekliğin aracı rolü test edilmiştir. Paternalist liderliğin, otoriter liderlik haricinde tüm alt boyutlarının (aile, iş dışı, sadakat) işe adanmışlı̆̆ın alt boyutları üzerindeki etkisinde; sıkılık-esneklik kısmi aracılık rolüne sahiptir. Otoriter liderlik alt boyutunun işe adanmışlığın üç alt boyutu üzerindeki etkisinde, skkılık-esnekliğin tam aracllık etkisine sahip olduğu görülmüştür. Bu testler, yazımda sayfa kısıtı olduğundan makalede ayrıca gösterilememiştir.

Bu kısımda yapılan basit doğrusal regresyon analizi ile $\mathrm{H}_{3}$ hipotezi test edilmiştir. Analiz sonucu tablo 13'te görülmektedir.

Tablo 13. Dönüşümsel Liderliğin, İşe Adanmışlık Üzerindeki Etkisine Yönelik Basit Doğrusal Regresyon Analizi

\begin{tabular}{|c|c|c|c|c|c|c|}
\hline \multicolumn{7}{|c|}{ Dönüşümsel Liderlik ile İşe Adanma Analizi } \\
\hline \multirow{2}{*}{\multicolumn{2}{|c|}{ Model }} & \multicolumn{2}{|c|}{$\begin{array}{l}\text { Standardize } \\
\text { edilmemiş katsayılar }\end{array}$} & $\begin{array}{l}\text { Standardize } \\
\text { katsayılar }\end{array}$ & $\mathrm{T}$ & $\mathrm{p}$ \\
\hline & & $\mathrm{B}$ & Std. Hata & Beta & & \\
\hline \multirow{2}{*}{1} & Sabit & 2,792 & ,347 & & 8,039 & ,000 \\
\hline & Dönüşümsel liderlik & 513 & 061 &, 595 & 8,431 & 000 \\
\hline
\end{tabular}

Bağımlı Değişken: İşe Adanma Bağımsız Değişken: Dönüşümsel Liderlik

R: 0,595; R2: 0,354; Düzeltilmiş R²: 0,349; Model için F: 71,086

Tablo 13 incelendiğinde, dönüşümsel liderliğin işe adanma üzerinde anlaml etkisinin olduğu görülmüştür $(\beta=0,595, p<0,05)$. Dönüşümsel liderliğin işe adanma toplam varyansının \%34,9'unu açıklandığı bulunmuştur. Sıkılıkesnekliğin, dönüşümsel liderliğin işe adanmışlık üzerindeki etkisindeki aracılık rolünü test etmek için tablo 14 ve 15 'teki analizler yapılmıştır. 
Tablo 14. Dönüşümsel Liderliğin, Sıkılık-Esneklik Üzerindeki Etkisine Yönelik Basit Doğrusal Regresyon Analizi

\begin{tabular}{|c|c|c|c|c|c|c|}
\hline \multicolumn{7}{|c|}{ Dönüşümsel Liderlik ile Sıkılık-Esneklik Analizi } \\
\hline \multirow{2}{*}{\multicolumn{2}{|c|}{ Model }} & \multicolumn{2}{|c|}{$\begin{array}{l}\text { Standardize } \\
\text { edilmemiş katsayılar }\end{array}$} & $\begin{array}{l}\text { Standardize } \\
\text { katsayılar }\end{array}$ & $\mathrm{T}$ & $\mathrm{p}$ \\
\hline & & $\mathrm{B}$ & Std. Hata & Beta & & \\
\hline \multirow{2}{*}{1} & Sabit & 1,743 &, 556 & & 3,135 &, 002 \\
\hline & Dönüşümsel liderlik & ,500 & ,098 & ,408 & 5,119 & 000 \\
\hline
\end{tabular}

Bağımlı Değişken: Sıkılık-Esneklik Bağımsız Değişken: Dönüşümsel Liderlik

R: 0,408; R2: 0,167; Düzeltilmiş R²: 0,160; Model için F: 26,205

Tablo 14 incelendiğinde, dönüşümsel liderliğin sıkılık-esneklik üzerinde anlamlı etkisinin olduğu görülmüştür $(\beta=0,408$, $\mathrm{p}<0,05)$. Dönüşümsel liderliğin sıkılık-esneklik toplam varyansının \%16'sını açıklandığı bulunmuştur. Sik1lık-esnekliğin işe adanmışlık üzerindeki etkisine yönelik regresyon analizi sonuçları yukarıdaki tablo 10 'da daha önce gösterildiğinden burada tekrar gösterilmemiştir.

Tablo 15. Dönüşümsel Liderlik ve Sıkılık-Esnekliğin, İşe Adanmışlık Üzerindeki Etkisine Yönelik Hiyerarşik Regresyon Analizi (Aracılık Testi)

\begin{tabular}{|c|c|c|c|c|c|c|}
\hline \multicolumn{7}{|c|}{ Dönüşümsel Liderlik ve Sıkılık-Esneklik ile İşe Adanma Analizi } \\
\hline \multirow{2}{*}{\multicolumn{2}{|c|}{ Model }} & \multicolumn{2}{|c|}{$\begin{array}{l}\text { Standardize } \\
\text { edilmemiş katsayılar }\end{array}$} & $\begin{array}{l}\text { Standardize } \\
\text { katsayllar }\end{array}$ & \multirow[t]{2}{*}{$\mathrm{T}$} & \multirow[t]{2}{*}{$\mathrm{p}$} \\
\hline & & $\mathrm{B}$ & Std. Hata & Beta & & \\
\hline \multirow{3}{*}{1} & Sabit & 2,512 & ,351 & & 7,157 & ,000 \\
\hline & Dönüşümsel Liderlik & ,438 & ,064 &, 508 & 6,812 & ,000 \\
\hline & Sıkılık-Esneklik & ,153 & 052 & 218 & 2,919 & 004 \\
\hline
\end{tabular}

Bağımlı Değişken: İşe Adanmışlık Bağımsız Değişken: Dönüşümsel Liderlik ve Sıkılık-Esneklik R: 0,627; R2: 0,394; Düzeltilmiş R2: 0,384; Model için F: 41,875

Tablo 15 incelendiğinde, dönüşümsel liderlik ve sıkılık-esnekliğin birlikte işe adanma üzerinde anlamlı etkisinin olduğu görülmektedir (Dönüşümsel liderlik $\beta=0,508$, sıkılık-esneklik $\beta=0,218, \mathrm{p}<0,05)$. Dönüşümsel liderlik ve s1kılık-esnekliğin birlikte işe adanmanın toplam varyansının \%38,4'ünü açıladığı belirlenmiştir. Bu duruma göre sıkılık-esnekliğin, dönüşümsel liderliğin işe adanmışlık üzerindeki etkisinde kısmi aracılık etkisine sahip olduğu söylenebilir. Bu aracılık etkisinin anlamlı olup olmadığını görmek için Tablo 16 'daki Sobel testi yapılarak, aracılık etkisi teyit edilmiştir. 
Tablo 16. Sobel Testi - Dönüşümsel Liderliğin İşe Adanmışlık Üzerindeki Etkisinde Sıkılık-Esnekliğin Aracı Rolü

\begin{tabular}{llllll}
\hline Girdi & & Test & Test İstatistikleri & Std Sapma & p-değeri \\
\hline $\mathrm{a}$ & 0,500 & Sobel & 3,65887775 & 0,04017625 & 0,00025332 \\
$\mathrm{~b}$ & 0,294 & Aroian & 3,62521257 & 0,04054935 & 0,00028872 \\
$\mathrm{Sa}$ & 0,098 & Goodman & 3,69349858 & 0,03979966 & 0,00022119 \\
$\mathrm{Sb}$ & 0,056 & & & & \\
\hline
\end{tabular}

Ayrıca değişkenlerin alt boyutları ile ilgili de analizler yapılmıştır. Buna göre dönüşümsel liderliğin alt boyutlarından; entelektüel uyarım, ilham veren motivasyon ve bireysel ilginin, işe adanmışlığın alt boyutları (dinçlik, adanma, özümseme) üzerindeki etkisinde; sıkılık-esneklik kısmi aracılık rolüne sahip olduğu belirlenmiştir. Sobel testi ile kısmi aracllık etkileri teyit edilmiştir. Dönüşümsel liderliğin ideal etki alt boyutunun; işe adanmışlı̆ı̆n dinçlik ve adanmışlık alt boyutları üzerindeki etkisinde sıkılık-esnekliğin aracı rolü bulunmamaktadır. İdeal etkinin, işe adanmışlı̆̆ın alt boyutu olan özümseme üzerindeki etkisinde sıkılık-esnekliğin aracı rolü ise sobel testi yapıldığında teyit edilememiştir.

\section{Sonuçlar}

Yapılan çalışmanın sonuçlarına göre hem paternalist hem de dönüşümsel liderliğin işe adanmışlık ve sıkılık-esneklik kültür boyutu üzerinde pozitif ve anlamlı bir etkisinin olduğu görülmektedir. Uluslararası literatür incelendiğinde liderlik tarzlarının örgüt kültürü üzerinde anlamlı bir etkisinin olduğu görülmektedir (Acar, 2013; Bakan, 2008; Barut ve Onay, 2018; Erdem ve Dikici, 2009; Schein, 1992; Korkmaz, 2007). Acar (2013)'ın çalışmasında ise klan ve hiyerarşi kültürlerinin dönüşümcü liderlikten etkilendiği belirlenmiştir. Aktaş, vd. (2016)'nın çalışmalarında sıkılık-esneklik ile katılımc liderlik, otonom liderlik, karizmatik liderlik ve kendini koruyan liderlik arasındaki ilişki araştırılmıştır. Dolayısıyla, bu araştırmanın bulguları ile literatür benzerlik göstermektedir.

$\mathrm{Bu}$ araştırmanın odaklandığı esas konu araştırma modelinde yer alan iki liderlik tarzının çalışanların işe adanmışlık tutumları üzerindeki etkisinde s1kılık-esneklik kültür boyutunun aracılık rolünü belirleyebilmektir. Araştırma sonuçlarına göre katılımcıların çalıştıkları örgüt normlarını daha esnek olarak 
algıladıkları görülmüştür. Literatürde ise durum farklıdır. Literatür incelendiğinde Gelfand vd. (2011)'nin yaptıkları araştırmada Türkiye'nin kültürünün ortalamaya göre daha sıkı olduğu görülmüştür (Özeren vd., 2013). Hatta, Uz (2015) tarafından 68 ülkenin sıkılık esneklik değerlerinin karşılaştırıldığı çalışmada Türkiye'nin en sıkı kültüre sahip 6. ülke olduğu belirlenmiştir. Ayrıca, Aycan ve Kanungo (2000) tarafından yapılan bir diğer çalışmada paternalist kültürlerde, astların görevinin koşulsuz şartsız liderin kurallarına uymak olduğu belirlenmiştir. Bu sonuçlar paternalist eğilimler gösteren toplumlarda, kural ve normlara uyumun önemli olduğunu ya da paternalist kültürlerde örgüt kültürünün daha sıkı olduğunu göstermektedir (Özeren vd., 2013). Ancak bu araştırmanın, çalışanların örgüt normlarını daha esnek alg1laması bulgusu ülke ortalamasına göre farklılık göstermiştir. Bu durum için her örgütün kendi yönetsel dinamikleriyle (liderlik tarzı burada esas faktör olarak görülebilir) ülke normlarının ötesinde kendine özgü kültürel normlarını oluşturduğunu söyleyebiliriz. Yine literatürde bahsedildiği gibi liderlik tarzları örgütün kültürel normlarının oluşmasında başat faktör olabilmektedir. Çalışmanın bir diğer temel bulgusu ise sıkılık-esnekliğin liderlik tarzları ile işe adanmışlık arasındaki ilişkide kısmi aracılık etkisine sahip olduğudur.

Çalışmada, paternalist liderliğin ve işe adanmışlığın alt boyutları dikkate alındığında; aile ortamı yaratma, iş dışı konularda katılım, sadakat ve itaat boyutlarının işe adanmışlı̆̆ın üç alt boyutu üzerindeki etkisinde sıkılık-esneklik kısmi aracılık etkisine sahiptir. Shu (2015) çalışmasında, otoriter liderliğin işe adanmışlık üzerinde negatif yönlü bir etkisi olduğunu, Cenkçi veÖzçelik (2015) ise literatürün aksine otoriter liderliğin işe adanmışlık üzerinde etkisi olmadığını bulmuştur. Bizim çalışmamızda ise otoriter liderliğin dinçlik ve adanmışlık alt boyutları üzerindeki etkisinde sıkılık-esnekliğin tam aracllık etkisine sahip olduğu bulunmuştur. Bu farklılı̆̆ın da yine örgütün kendi yönetsel dinamiklerinden kaynaklandığı tahmin edilmektedir. Dönüşümsel liderliğin ve işe adanmışlı̆ın alt boyutları dikkate alındığında; entelektüel uyarım, ilham veren motivasyon ve bireysel ilginin, işe adanmışlı̆ı̆n alt boyutları (dinçlik, adanma, özümseme) üzerindeki etkisinde; sıkılık-esneklik kısmi aracılık rolüne sahiptir. İdeal etki alt boyutunun işe adanmışlı̆̆ın alt boyutları üzerindeki etkisinde ise; sıkılık-esnekliğin, bir aracllık etkisi bulunmamaktadır.

Çalışmanın bir diğer sonucu ise çalışanların işe adanmışlık tutumları üzerinde dönüşümsel liderliğin göreceli olarak paternalist liderlikten daha etkili 
olduğudur. Kurumsallaşma sürecini tamamlamamış, hem yönetimsel (liderlik tarzı olarak) hem de yapısal olarak daha çok tipik bir aile işletmesi karakteristiğini gösteren işletmede, paternalist liderlik tarzının daha baskın olması beklenirken dönüşümsel liderliğin göreceli olarak daha yüksek olmasında paternalist liderlik içerisinde kullanılan otoriterlik alt boyutunun genel ortalamayı düşürmesi bir neden olarak söylenebilir.

Bu araştırma sonucuna göre dönüşümsel ve paternalist liderlik tarzlarının çalışanların işe adanma tutumları üzerinde önemli bir etkisinin olduğu ayrıca bu liderlik tarzlarının örgüt kültürünün oluşmasında etkili olduğu, sıkılıkesneklik kültür değişkeninin liderlik tarzları ile işe adanma arasında kısmi aracılık etkisine sahip olduğu belirlenmiştir. Her ne kadar örgüt kültürü sıkı değil de esneklik yönünde eğilim gösterse de bu liderlik tarzının o örgüte özgün bir sonucu olduğu söylenebilir. Bu çalışmanın en önemli kısıtı üretim yapılan tek bir işletme üzerinde uygulanmış olması ve çalışmanın diğer sektör ve Türkiye evrenine genellenemeyeceğidir. Diğer yandan bu alandaki araştırmacılar homojenlik gösteren farklı sektörlerde bu çalışmayı uygulayabilirler. Uygulamacıların ise dönüşümcü ve paternalist liderlik tarzları ile birlikte sıkılık-esneklik kültür boyutunu da dikkate alarak yapacakları yönetim tarzlarıyla çalışanlarının işe adanmışlık vb. gibi olumlu iş tutumu geliştirmelerine katkı sağlayabilecekleri söylenebilir. 


\section{EXTENDED ABSTRACT}

\section{Mediating Role of Tightness-Looseness on the Effect of Paternalistic and Transformational Leadership Style on Work Engagement}

Kemal Can Kılıç-Işıl Deniz Toker-Duygu Karayel-Tuğba Soyman-Gözde Zengin Çukurova University

Aim: The aim of this research is to find out the effect of paternalistic and transformational leadership styles on work engagement and the mediating effect of tightness-looseness culture dimension on this effect, at a company operating in food industry and has 150 employees in the main plant.

$\operatorname{Method(s):~In~the~study;~a~literature~review~is~completed~about~paternalistic~}$ and transformational leadership styles, tightness-looseness of an organization and work engagement. After literature review; a food manufacturing company is chosen for doing research; which is competing at a highly competitive market that requires engagement of employees, whose leadership style is sometimes authoritarian other times employees are treated like a family member, whose culture is sometimes loose sometimes tight. So the company chosen allows researching relevant variables and testing the hypothesis. After determining the company, an exploratory (qualitative) research is completed by interviewing the chairman of the executive board. In this qualitative research, it's observed that the company is run as a family business, paternalistic leadership style seems to be more predominant throughout the company and although management aims for a more formal structure, the company seems to have a more loose culture. After this pre-research, general structure of the main research is determined. The questionnaire included scales for evaluating paternalistic leadership with 17 questions and 4 sub-dimensions, transformational leadership with 20 questions and 4 sub-dimensions, tightness-looseness with 5 questions in one dimension and work engagement with 9 questions under 3 sub-dimensions. Including demographic questions, the survey has 57 questions in total. 7 point Likert scale is used in the survey. In the main research part, 133 employees out of 150 main plant employees completed the questionnaire $(\% 88,6)$. Data collected via the survey is analyzed by 
SPSS Statistical Package with 95\% confidence interval. Factor analysis and regression analysis is used for testing the hypothesis. Also, sobel test is used for confirmation of the mediating effect.

- $\mathrm{H}_{1}$ : Paternalistic leadership style has a positive and significant effect on work engagement

- $\mathrm{H}_{2}$ : Tightness-looseness has a mediating role on the effect of paternalistic leadership style on work engagement

- $\mathrm{H}_{3}$ : Transformational leadership style has a positive and significant effect on work engagement

- H4: Tightness-looseness has a mediating role on the effect of transformational leadership style on work engagement

Findings: According to the findings, $91 \%$ of participants are men and \% 86 are between $25-44$ years old. $47 \%$ has a high school degree, $32 \%$ has less than high school degree and $20 \%$ has more than high school degree. In 7 point scale, mean of each of the variable and sub-variables are in between 4.35 and 5.72 and skewness kurtosis values show that the data has a normal distribution. Mean of tightness-looseness variables is 4.48 , which indicates a loose culture. The scales used in the questionnaire are reliable, cronbach alfa values are between 0.78 and 0.95. KMO and Bartlett's test is used to determine whether factor analysis can be applied to our data. For all variables, KMO value ise higher than 0.60 and each scale is evaluated in number of dimensions stated above. Because factor loading of $8^{\text {th }}$ question in ideal effect dimension of transformational leadership scale and $2^{\text {nd }}$ question of family environment at workplace dimension of paternalistic leadership scale is below 0.5 , these questions are excluded from the analysis. Hypothesis are tested with simple linear regression. According to the findings of regression analysis, both of the leadership styles has a positive and significant effect on work engagement and tightness-looseness culture has a partial mediating role on this effect. Considering sub-dimensions of transformational leadership and work engagement; tightness-looseness has a partial mediating role on the effect of three sub-dimensions of transformational leadership (intellectual stimulation, inspirational motivation and individualized consideration) on subdimensions of work engagement (vigor, dedication, absorption). Tightnesslooseness doesn't have a mediating effect on the effect of idealized influence sub-dimension of transformational leadership on sub-dimensions of work 
engagement. In paternalistic leadership scale, four sub-dimensions with eigenvalues bigger than 1 can explain $50.37 \%$ of total variance. In transformational leadership scale, four sub-dimensions with eigenvalues bigger than 1 can explain $68.14 \%$ of total variance. In tightness-looseness scale, one sub-dimension with eigenvalues bigger than 1 can explain $64.96 \%$ of total variance. In work engagement scale, three sub-dimensions with eigenvalues bigger than 1 can explain $67.75 \%$ of total variance. Transformational leadership style can explain $34.9 \%$ of total variance in work engagement $\left(R^{2}=0,349\right)$ Paternalistic leadership style can explain $25.4 \%$ of total variance in work engagement $\left(R^{2}=0,254\right)$.

Conclusion: As a result of this study, it is revealed that paternalistic leadership style and transformational leadership style both have a positive and significant effect on work engagement and tightness-looseness culture has a partial mediating role on this effect. When the literature is reviewed, it's found that leadership styles have significant effect on organizational culture (Acar, 2013; Aktaş, 2016; Bakan, 2008; Barut ve Onay, 2018; Erdem ve Dikici, 2009; Schein, 1992; Korkmaz, 2007). So, the findings of our research is consistent with the literature. In this research, it's found out that employees perceive the company culture as more loose. In the literature, Gelfand (2011) has found out that Turkey has a more tight culture compared to the average (Özeren et al., 2013). In the company that is researched, which is run as a family business, paternalistic leadership style is expected to be more predominant than transformational leadership style, but the analysis show the opposite, which can be attributed to authoritarian leadership sub-dimension that is included as an extra-dimension in paternalistic leadership scale. Another finding is that, compared to paternalistic leadership, transformational leadership can explain change in work engagement better, so in order to increase work engagement, besides paternalistic leadership, focusing on transformational leadership seems a good alternative.

\section{Kaynakça / References}

Acar, A. Z. (2013). Farklı örgüt tipleri ve liderlik tarzları ile örgütsel bağlllık ilişkisi: Lojistik işletmelerinde bir araştırma. İşletme Araştırmaları Dergisi. 5(2), 5-31. 
Aktaş, M., Gelfand, M. J., Hanges, P. J. (2016). Cultural tightness-looseness and perceptions of effective leadership. Journal of Cross-Cultural Psychology, 47(2), 294-309.

Arslantaş, C. C. ve Pekdemir, I. (2007). Dönüşümcü liderlik, , örgütsel vatandaşlık davranışı ve örgütsel adalet arasındaki ilişkileri belirlemeye yönelik görgül bir araştırma. Anadolu Üniversitesi Sosyal Bilimler Dergisi, 7(1).

Aycan Z. (2006). Paternalism. (U.Kim, KS.Yang, KK Hwang. Ed.) Indigenous and Cultural Psychology. International and Cultural Psychology. Springer, içinde (s.445-466), Boston:MA, ISBN: 978-0-387-28662-4 https://doi.org/10.1007/0-387-28662-4_20

Aycan, Z. ve Fikret-Pasa, S. (2003). Career choices, job selection criteria, and leadership preferences in a transitional nation: The case of Turkey. Journal of Career Development, 30(2), 129-144. https://doi.org/10.1177/089484530303000203. Erişim tarihi: 10.3.2019

Aycan, Z., Kanungo, R. N., Mendonca, M., Yu, K., Deller, J., Stahl, G. ve Kurshid, A.(2000).Impact of culture on human resource management practices:A 10country comparison.Applied Psychology:An International Review,49,192-221.

Aycan, Z., Schyns, B., Sun, J., Felfe, J. ve Saher, N. (2013). Paternalistic leadership questionnaire (PLQ) short version. 10.3.2019 tarihinde zeynepaycan.net/doc/p1.pdf adresinden erişilmiştir.

Babcock-Roberson, M. E. ve Strickland, O. J. (2010). The relationship between charismatic leadership, work engagement, and organizational citizenship behaviors, The Journal of Psychology, 144(3), 313-326, DOI: 10.1080/00223981003648336. doi.org/10.1080/00223981003648336

Bakan, İ. (2008). “Örgüt kültürü" ve "liderlik” türlerine ilişkin algılamalar ile yöneticilerin demografik özellikleri arasındaki ilişki: Bir alan araştırması. KMU IIBF Dergisi (Sosyal ve Ekonomik Araş,trmalar Dergisi, 10(14), 13-40.

Bal, E. A. (2008). Self-efficacy, contextual factors and well-being: The impact of work engagement. Yayımlanmamış Doktora Tezi. Marmara Üniversitesi Sosyal Bilimler Enstitüsü İstanbul.

Baloğlu, N., Karadağ, E. ve Gavuz, Ş. (2009). Okul müdürlerinin çok faktörlü liderlik stillerinin yetki devrine etkisi: Bir doğrusal ve yapısal eşitlik modelleme çalışması. Uludă̆ Üniversitesi Eğitim Fakültesi Dergisi, 22(2), 457-479.

Barut, Y., Onay, M. (2018). Orgüt kültürü ve liderlik tarzı arayışında yeni argümanlar: Manisa Vestel Fabrikasında Bir Çalışma. Uluslararası Bilimsel Araştırmalar Dergisi, 3(1), 181-193 
Bass, B. M. ve Avolio, B. J. (1993). Transformational leadership and organizational culture. Public Administration Quarterly, 17(1), 112-121.

Cenkci, A.T. ve Ozçelik, G. (2015). Leadership styles and subordinate work engagement: The moderating impact of leader gender. Global Business and Management Research: An International Journal, 7(4), 8-20.

Cerit, Y. (2012). Paternalist liderlik ile yöneticiden ve işin doğasından doyum arasındaki ilişki. Ondokuz Mayıs Üniversitesi Ĕ̆itim Fakültesi Dergisi, 31(2), 35-56.

Cheng, B. S., Chou, L. F., Wu, T. Y., Huang, M. P. ve Farh, J. L. (2004). Paternalistic leadership and subordinate responses: Establishing a leadership model in Chinese organizations. Asian Journal of Social Psychology, 7, 89-117.

Chungtai, A.A. ve Buckley, F. (2008). Work engagement and its relationship with state and trait trust: a conceptual analysis. Journal of Behavioral and Applied Management, 10(1), 47-71

Çapri, B., Gündüz, B. ve Akbay, S. E. (2014). Utrecht work engagement scale-student forms' (UWES-SF) adaptation to Turkish, validity and reliability studies, and the mediator role of work engagement between academic procrastination and academic responsibility. Education Sciences: Theory $\mathcal{E}$ Practice, 17(2) 411-435. DOI: 10.12738/estp.2017.2.0518

Çağlar, E. S. (2012). Work engagement, empowerment and leadership styles: Analyses from cultural perspectives in hotel management. Journal of Global Strategic Management, 6(1), 17-31. Doi:10.20460/JGSM.2012615783

Enwereuzor, I. K., Ugu, L. I. ve Eze, O. A. (2018). How transformational leadership influences work engagement among nurses: Does person-job fit matter? Western Journal of Nursing Research, 40(3) 346-366. DOI: $10.1177 / 0193945916682449$.

Eraslan, L. (2004). Liderlikte post-modern bir paradigma: Dönüşümcü liderlik. Uluslararası Insan Bilimleri Dergisi, 1(1), 1-32.

Erben, G. ve Ötken, A. (2014). Paternalist liderlik ve işe bağlı mutluluk ilişkisinde iş-yaşam dengesinin rolü. Yönetim ve Ekonomi Araştırmaları Dergisi, 12 (22), 103-121.

Erdem, O., Dikici, A. M. (2009). Liderlik ve kurum kültürü etkileşimi. Elektronik Sosyal Bilimler Dergisi, 8(29), 198-213 ISSN:1304-0278

Erim, F. N. A. (2009). Individual response to organizational change: Creating facade of conformity its antecedents and effects on participating in decision making, work engagement, job involvement and intent to quit. Yayımlanmamıs Doktora Tezi. Marmara Universitesi Sosyal Bilimler Enstitüsü, Istanbul. 
Gelfand, M. J., Raver, J. L., Nishii, L. H., Leslie, L. M., Lun, J., Lim, B. C., Duan, L., ..., Yamaguchi, S. (2011). Differences between tight and loose cultures: A 33nation study. Cornell University. 20.7.2019 tarihinde https:/digitalcommons.ilr.cornell.edu/articles/1287 adresinden erişilmiştir.

Gelfand, M. J., Nishii, L. H.,Raver, ve Jana, L. (2006). On the nature and importance of cultural tightness-looseness. Journal of Applied Psychology, 91(6), 1225-1244

Ghadi, M.Y., Fernando, M. ve Caputi, P. (2011). Transformational leadership and work engagement: The mediating effect of meaning in work. Leadership E Organization Development Journal, 34(6),532-550, 2.3.2019 tarihinde https://doi.org/10.1108/LODJ-10-2011-0110 adresinden erişilmiştir.

Gül, H. ve Şahin, K. (2011). Bilgi toplumunda yeni bir liderlik yaklaşımı olarak transformasyonel liderlik ve kamu çalıs,anlarının transformasyonel liderlik algısı. Selçuk Üniversitesi Sosyal Bilimler Enstitüsü Dergisi, 25, 237-249.

Gündüz, Y. (2015). Etkıleşimsel ve dönüşümsel liderlik tarzlarının izleyicilerinin örgütsel güç algısı üzerindeki etkisini incelemeye yönelik bir araştırma. Yüksek Lisan Tezi, Marmara Üniversitesi, İstanbul.

Gündüz, B., Çapri, B. ve Gökçakan, Z. (2013). Mesleki tükenmişlik, işle buitünleşme ve iş doyumu arasındaki ilişkilerin incelenmesi . Eğitim Bilimleri Araş,trmaları Dergisi-Journal of Educational Sciences Research, 3(1), 29-49.

Güneşer, A. B. (2007). The effect of person-organization fit on organizational commitment and work engagement: the role of person supervisor fit. Yayımlanmamış Doktora Tezi. Marmara Üniversitesi Sosyal Bilimler Enstitüsü, İstanbul.

Kırel, Ç. (2001). Liderlik davranış biçimleri konusuna yeni bir yaklaşım: Karizmatik liderlikten dönüşümsel liderliğe. Anadolu Üniversitesi Sosyal Bilimler Dergisi, 1(1), 43-59.

Korkmaz, F., Gökdeniz, İ. ve Zorlu, K. (2018). Paternalist liderlik davranışının örgütsel özdeşleşme üzerindeki etkisinde çalışanların işe tutkunluk düzeylerinin aracılık rolü. Isşletme Araştırmaları Dergisi Journal of Business Research-Turk, 10(3) 950-973.

Korkmaz, M. (2007). Orguitsel saglık üzerinde liderlik stillerinin etkisi. Kuram ve Uygulamada Egĭtim Yönetimi, 49, 57-91.

Mathur, P., Aycan, Z. ve Kanungo, R. N. (1996). Work cultures in Indian organizations: A comparison between public and private sector. Psychology and Developing Societies, 8(2), 199-223. 
Mittal, R. (2015). Charismatic and transformational leadership styles: A Cross-cultural perspective. International Journal of Business and Management; 10(3). ISSN:1833-3850 E-ISSN:1833-8119.

Naidoo, P. ve Martins, N. (2014). Investigating the relationship between organizational culture and work engagement. Problems and Perspectives in Management, 12(4), 432-440.

Öge, E., Çetin, M. ve Top, S. (2018). The effects of paternalistic leadership on workplace loneliness, work family conflict and work engagement among air traffic controllers in Turkey. Journal of Air Transport Management, 66, 2535. http://dx.doi.org/10.1016/j.jairtraman.2017.10.003

Oner, Z. H. (2008). The Mediating effect of organizational justice: Moderating roles of sense of coherence and job complexity on the relationship between servant leadership, and work engagement. Yayınlanmamıs Doktora Tezi. Marmara Universitesi, Sosyal Bilimler Enstitüsü, Istanbul.

Öner, Z. H. (2012). Servant leadership and paternalistic leadership styles in the Turkish business context: A comparative empirical study. Leadership $\mathcal{E}$ Organization Development Journal, 33(3), 300-316, https://doi.org/10.1108/01437731211216489. Erişim tarihi: 17.3.2019

Özeren, E., Özmen, O. N. T. ve Appolloni, A. (2013). The relationship between cultural tightness-looseness and organizational innovativeness: A comparative research into the Turkish and Italian marble industries. Entrepreneurship and International Management. Transit Stud Rev, 19, 475-492. DOI:10.1007/s11300-013-0262-x

Özkalp, P. D. E. ve Meydan, P. D. B. (2015). Schaufelï Ve Bakker tarafindan geliştirilmiş olan işe angaje olma ölçeğïnïn Türkçe'de güvenilïrlik ve geçerliliğininin analizii. İş, Güç, Endüstri İlişkileri ve Insan Kaynakları Dergisi, 17(3), ISSN: 2148-9874.

Pellegrini, E. K. ve Scandura, T. A. (2006). Leader-member exchange (LMX), paternalism and delegation in the Turkish business culture: An empirical investigation. Journal of International Business Studies, 37(2), 264-279.

Pellegrini, E. K. ve Scandura, T. A. (2008). Paternalistic leadership: A review and agenda for future research. Journal of Management. 34(3), 566-593. https://doi.org/10.1177/0149206308316063

Pelto, P. J. (1968). The difference between "tight" and "loose" societies. Trans-action, 5, 37-40. Springer-Verlag. ISSN:1936-4725. https://doi.org/10.1007/BF03180447 
Sakal, Ö. ve Macit, R. (2018). Sıkllık-esneklik ve performans: Psikolojik güçlendirmenin aracı rolü. Social Sciences Studies Journal, SSSjournal. 4(21). ISSN:2587-1587

Salanova, M., Lorente, L., Chambel, M. L. ve Martinez, I. M. (2011). Linking transformational leadership to nurses' extra-role performance: the mediating role of self-efficacy and work engagement, Journal of Advanced Nursing. 67(10), 2256-66. doi: 10.1111/j.1365-2648.2011.05652.x.

Sarros, J. C ve Santora, J. C. (2001). The transformational-transactional leadership model in practice. Leadership \& Organization Development Journal, 22(8), 383-394. doi:10.1108/01437730110410107

Schaufeli, W. B., Martinez, I., Marques-Pinto, A., Salanova, M. ve Bakker, A. (2002). Burnout and engagement in university students: A cross-national study. Journal of Cross-cultural Studies, 33, 464-481.

Schaufeli, W. ve Bakker, A. (2004). Utrecht work engagement scale. Preliminary. Occupational Health Psychology Unit, Utrecht University.

Shu, C. (2015). The impact of intrinsic motivation on the effectiveness of leadership style towards on work engagement. Contemporary Management Research, 11(4), 327-350. https://doi.org/10.7903/cmr.14043

Turgut, T. (2011). Calış̧maya tutkunluk: İş yükü esnek çalışma saatleri. Yönetici desteği ve iş- aile çatışması ile ilişkileri. Atatü̈k Univiversitesi Iktisadi ve Idari Bilimler Dergisi, 25 (3-4), 155-179.

Uz, İ. (2015). The Index of Cultural tightness and looseness among 68 countries. Journal of Cross-Cultural Psychology, 46(3) 319-335.

Üstün, F. ve Kılıç, K. C. (2017). Sıkılık-esneklik kültür boyutunun yönetsel ve yapısal çeşitli değişkenlere göre incelenmesi: Türkiye'nin öncü sanayi işletmeleri üzerine bir araştırma. Gaziantep University Journal of Social Sciences, 16 (4), 963-979.

Wasti, A. ve Fiş, A.M. (2010). Örgüt kültüründe sıkılık-esneklik boyutu ve kurumsal girişimciliğe etkisi. Yönetim Araştırmaları Dergisi, 10, 11-32.

Yolaç, S. (2012). Yöneticinin algilanan liderlik tarzi ile yöneticiye duyulan güven arasindaki ilişkide lider üye etkileşiminin rolü. Öneri Dergisi, 9(36), 63-72.

Zhu, W., Avolio, B. J. ve Walumbwa, F. O. (2009). Moderating role of follower characteristics with transformational leadership and follower work engagement. Group \& Organization Management, 34(5), 590-619. 20.3.2019 tarihinde http://dx.doi.org/10.1177/1059601108331242 adresinden erişilmiştir. 


\section{Kaynakça Bilgisi / Citation Information}

Kılıç, K. C., Toker, I. D., Karayel, D., Soyman, T. ve Zengin, G. (2020) Paternalist ve dönüşümsel liderlik tarzlarının işe adanmışlık üzerindeki etkisinde, sıkılık-esneklik değişkeninin aracılık rolü. OPUSUluslararası Toplum Araştırmaları Dergisi , 15(24), 2875-2911. DOI: 10.26466/opus.597712 